\title{
Warm Glow from Green Power: Evidence from Australian Electricity Consumers*
}

Chunbo Ma (Chunbo.ma@uwa.edu.au ), Michael Burton (Michael.burton@uwa.edu.au)

†School of Agricultural and Resource Economics, Centre for Environmental Economics and Policy, University of Western Australia

\section{Corresponding Author}

\section{Michael Burton}

Email: michael.burton@uwa.edu.au

Tel: (61) 864882531

Fax: (61) 864881098

Postal: School of Agricultural and Resource Economics, Centre for Environmental Economics and Policy, University of Western Australia

\section{JEL Classification}

Q42; Q48, Q51; Q58

\section{Working Title}

Warm Glow from Green Power

\footnotetext{
* This project received financial support from the Australian Research Council (ARC DECRA 130100996), the Research Development Award at the University of Western Australia. We thank session attendants at the International Choice Modelling 2013 Conference and the Australian Agricultural and Resource Economics Society's 2014 annual conference for many valuable comments. All remaining errors are ours.
} 


\section{Warm Glow from Green Power: Evidence from Australian Electricity Consumers}

\section{Abstract}

Green electricity products are increasingly made available to consumers in many countries in order to address a number of environmental and social concerns. Most of the literature on this green electricity market focuses on consumers' characteristics and product attributes that could affect participation. However, the contribution of this environmental consumerism to the overall environmental good does not depend on participation alone. The real impact relies on market participation for green consumers (the proportion of green consumers) combined with the level of green consumption intensity - the commitment levels, or proportion of consumption that is green. We design an online interface that closely mimics the real market decision environment for electricity consumers in Western Australia and use an error component model to analyze consumers' choice of green electricity products and their commitment levels. We show that product attributes have limited impact on the choice of green products; however, there is still great potential for better participation by improving the design of green electricity programs. When green products are selected, most respondents select the minimum commitment possible, and this is insensitive to the premium being charged on green power, suggesting that we are largely observing a buy-in 'warm glow' for carbon mitigation.

Keywords: Green Electricity, Choice Modelling, Error Components Model, Warm Glow JEL: Q42; Q48, Q51; Q58 


\section{Introduction}

The past few decades have witnessed a significant increase in the demand for and supply of "environmentally friendly" or "green" products. Market research on consumers' behavioural patterns involved in green product choice has shown an increasing percentage of consumers in many countries willing to buy green products (Landor Associates, 2011). However other market studies have also indicated that consumers may be only willing to purchase green products with preferred attributes within certain constraints. In particular, they may have a threshold price or payment level beyond which they are no longer willing to purchase green products (Blamey et al, 2001). In contrast, academic research in the area only focuses on the factors and attributes that influence consumers' choice of green products, or the extensive margin. Very little research looks at the level of commitment, or the intensive margin, defined here as the proportion of an individual's use of a product that is 'green'.

The environmental impact as a result of green consumption not only depends on consumers' choice of environmentally friendly products, but also the level of commitment. For instance, the contribution of residential rooftop solar panel adoption to a clean energy supply (and its associated public environmental good) depends on the size (capacity) of each installation as well as the number of installations. Andreoni (1989; 1990) argued that consumers derive "warm glow" utility from the contribution to the environmental good (which is pure altruism and is linked to the level of commitment). Kahneman and Knetsch (1992) also argued that the "warm glow of moral satisfaction" increases with the size of the contribution.

On the other hand, stated preference studies often found an "embedding" effect, where values do not appear to be sensitive to the scale of provision. Nunes and Schokkaert (2003) find that accounting for a lump sum "warm glow" (that is gained irrespective of contribution level but may vary across individuals) 
leads to "cold" measures of WTP that pass scope and adding up tests. Kotchen and Moore (2008) also infer a "lump sum" benefit from reduced conventional energy use that is consistent with "the existence of social and psychological benefits of the green-electricity program that are unrelated to electricity consumption" (p212). Jacobsen et al (2012) find evidence of a "buy-in" mentality (Rose-Ackerman, 1982), where purchasers of green electricity are concerned not about their overall level of emissions, but simply "buy-in" to the program at the minimum quantity possible, with $45 \%$ of respondents exhibiting that behavior. The amount that consumers are willing to pay has been found to be highly non-linear in the percent of energy that is generated from renewables (Farhar, 1999) and customers are more concerned about the concept of consuming green energy than its actual environmental impact (Goett et al., 2000). Jacobsen and Kotchen (2013) also find that community-level rewards can be effective in promoting consumer participation in green electricity programs, but the size of the reward itself appears less important. Overall, the literature has suggested a two-component warm glow effect: a buy-in warm glow irrespective of commitment level and a contribution warm glow that depends on the commitment level.

The relative magnitude of the two warm glow effects has significant implications for the consequences of programs (Harbaugh, 1998). If a buy-in "warm glow" effect plays a dominant role, the actual contribution to the environmental good may be limited even if there are a substantial number of green consumers. During the second quarter of 2013, Synergy (the principle supplier of energy to households in Perth, Western Australia) sold green electricity to 5,649 residential customers, which represents a roughly one percent penetration at the customer level (Synergy, 2013). However the latest quarterly statistics on actual green electricity sale to these green customers translates to a mere $31 \%$ average commitment level (GP, 2013) (assuming a representative household with 18-unit consumption 
per day). As a result of the low commitment level, the actual contribution to the environmental good is much less than the penetration level often considered at the customer level.

Consumers' decision making at the commitment level will have significant implications for the actual impact of policies that aim to promote pro-environmental behaviors. It is thus important to study both consumers' choice of green products (participation) and their commitment levels. In this paper, we study both elements of consumers' behavior in green electricity programs in Western Australia. We design a survey that closely mimics the real decision context facing consumers in Western Australia and use an error component discrete choice model to investigate both consumers' choices of products and commitment levels. The model allows us to investigate the circumstances under which both the buy-in "warm glow" effect and the contribution "warm glow" effect manifest themselves. In particular, it investigates whether the characteristics of the green energy program affect these behaviors. We also compare the implications of the model with historical data on engagement with green energy programs in WA. The rest of the paper proceeds as follows. Section 2 provides the background of Australian green electricity programs and reviews relevant literature. Section 3 describes our experimental design. Section 4 introduces our statistical model. We present results in Section 5 and conclusions in the last section.

\section{Background and Literature}

The option to purchase green electricity products is increasingly available to consumers in many countries. For instance, nearly 850 utilities in the US currently offer green electricity programs (DOE, 2015). In Australia, there are about 40 accredited green electricity schemes provided by utility retailers in Australia (GP, 2015). The willingness of consumers to pay for green electricity or actual participation in 
the green electricity market has been investigated in a large number of countries including the US (Farhar and Houston, 1996; Wiser, 2007; Bird et al., 2007; Kotchen and Moore, 2007; Conte and Jacobsen, 2014), Australia (Mewton and Cacho, 2011, Ivanova, 2012), Sweden (Ek and Söderholm, 2008), Norway (Navrud and Bråten, 2007), Finland (Salmela and Varho, 2006), UK (Scarpa and Willis, 2010; Diaz-Rainey, 2012), Germany (Menges et al., 2005), Canada (Rowlands et al., 2003) and Japan (Nomura and Akai, 2004). Most of these studies address two questions: 1) what motivates consumers to participate in green electricity programs? 2) how do consumers' characteristics and a product's attributes (e.g. energy sources and payment mechanisms) affect participation? For instance, Conte and Jacobsen (2014) provide a recent summary of revealed-preference studies of US green electricity programs. Most have focused on consumer participation in such programs with the exception of Jacobsen et al (2012). Conventional electricity is mostly generated from fossil fuels, which is by far the largest emitter of a number of local as well as global air pollutants, such as carbon and fine particulates. Demand for green electricity thus contributes to the mitigation of these pollutants. However, the contribution of this environmental consumerism to the overall environmental good does not depend on participation alone. If a buy-in "warm glow" effect is the dominant driver for participation, we would expect a low commitment level overall. As a result, the real impact of this green consumerism and policies promoting it may also be rather limited. It is thus important to investigate both participation and commitment levels.

Under all-or-none schemes, where consumers either choose a conventional electricity product or commit $100 \%$ to electricity generated from renewable sources, it is understandable that studies mostly focus on participation. However, this all-or-none approach is increasingly being moderated in real markets, with many green electricity products offering different commitment levels. In Australia, the green electricity market is largely driven by the Australian National Green Power Accreditation Program 
(NGPAP) which is a market-based program initiated by the NSW government in 1997. The objective of the program is to encourage investment in new renewable energy generation by increasing consumer demand and confidence in accredited Green Power (GP) products by letting consumers opt-in to pay a premium and buy more expensive green electricity on a voluntary basis. Currently, a total of 44 "GreenPower" products are provided by 28 NGPAP accredited retailers nationally. In addition, there are other unaccredited green electricity products offered in the market.

Synergy, which is the electric utility company that serves the metropolitan Perth area, offers residential customers two NGPAP accredited "GreenPower" products - "EasyGreen" (EG) and "NaturalPower" (NP), and one unaccredited product - "EarthFriendly" (EF). Consumers can make a choice between conventional electricity product and these accredited and unaccredited green electricity products. In addition, they can also choose the level of commitment through different payment schemes. For EG, consumers can commit to a fixed level of surcharge (ranging from $\$ 10$ - $\$ 80$ in $\$ 10$ steps) on top of their regular bill: i.e. the amount of green energy purchased is fixed, irrespective of total energy use. For NP or EF, customers can choose a fixed proportion of their electricity to be generated from renewable sources $(25 \%-100 \%)$ or choose to offset the carbon emission of a fixed proportion of their conventional electricity consumption $(25 \%-100 \%)$. The difference between NP and EF is the energy sources: NP is generated from renewable energy sources while EF is still conventional electricity but with a carbon offset. The premium payment from NP will contribute to renewable electricity generation and that for EF will contribute to carbon offsetting projects like planting trees. This green electricity market thus provides an excellent real market setting to study consumers' commitment levels as well as product choices. 
The majority of the WA households are served by Western Power's South West Interconnected Systems (SWIS). Synergy is responsible for the retail delivery of electricity in this area. The SWIS covers the entire metropolitan Perth area where we recruit all our respondents. Synergy provides an online interface for consumers to compare and make a choice among electricity products and commitment levels ${ }^{1}$. Information on the cost of selecting different products and commitment levels and associated environmental impacts is provided through the interactive interface. This online interface thus represents the real market decision environment that households face in the metropolitan Perth area. As noted by Collins et al (2012) the decision context normally presented to respondents in a stated preference study bears little resemblance to the context in which real decisions are made. A table of options, with rows of attributes, does not represent the way that people search across alternatives to make choices. They find that investigating travel choices using a representation of an online travel agency led to more consistent choice behavior. We follow this approach, by presenting the choice sets to respondents in a replication of the Synergy online interface. In the hypothetical experimental setting we slightly modify this interface to include an extra pane for each product which included additional information regarding the attributes of the electricity products, while trying to closely mimic the real market environment. Importantly, we also include a pane that allows for selection of regular power. In the actual market this option is the default, and consumers have to opt into the green products through the web page. In the experimental context this is not possible, and the regular power is selected as part of the process. This may have important implications for choices, which we return to in the discussion. Figure 1 and Figure 2 present images of Synergy's actual interface and our modified version where we embed our

\footnotetext{
${ }^{1}$ http://www.synergy.net.au/at_home/gogreen.xhtml
} 
choice experiments ${ }^{2}$

Consumers (respondents in our case) can navigate across products (tabs) to see attribute differences. They can also change commitment levels by moving the slider bar to see the extra cost to their electricity bill and the impact on the level of carbon emissions (shown in panel 2). The average daily electricity consumption is updated based on the respondent's answer to an earlier survey question about the household's typical utility bill. Once a consumer (respondent) is satisfied with a specific combination of a product and a commitment level, they can make an order (choice in our case). It is reasonable to think that consumers in the real market would need time to get familiar with the structure of the interface before they can make an order. To facilitate this process in our choice experiment, we provided a 5minute video demonstration to explain how to compare alternative products, adjust commitment levels and make a choice, and how many choice questions they will be asked to answer. This video was viewed before respondents started with the formal choice questions, and could not be avoided. Each respondent answered six choice sets. When setting the commitment level respondents were restricted to the discrete levels available: $\$ 10-\$ 80$ for EasyGreen (in steps of $\$ 10$ ), or $25,50,75,100 \%$ for NaturalPower and EarthFriendly ${ }^{3}$. Thus respondents can be considered to have selected 1 out of 4 products, if the analysis is considered at the product level, or 1 of 17 product/commitment levels, if one considers the full choice process.

Some people may have preferences that don't follow the assumed compensatory structure. For instance, some may always choose the conventional power regardless of the attribute levels of the green

\footnotetext{
2 Although Synergy approved the use of a simile of their web site, they are not responsible for any of the implementation and conclusions drawn from this study.

${ }^{3}$ These are also the actual discrete commitment levels marketed by Synergy.
} 
products. We embedded two features in the experimental design to capture such possible 'repeat" preferences. First, we included a seventh question after the six regular choice questions in which the premiums of the green products were restricted to zero. This was not part of the formal statistical design, but comprised a choice set where the premium for the green products was set to zero. Respondents with repeat preference for conventional power will not choose the green products even if the premium drops to zero. Selection of conventional power across all 7 choice sets will provide a strong indication of noncompensatory choice behaviour. Second, we recorded the time that respondents spent on each choice question. Ideally, time spent looking at each tab would be available, but it was not possible to provide this information. However, if those who always chose conventional power spent significantly shorter time on each choice question this indicates no consideration of the alternative green power products.

${ }^{4}$ We acknowledge that it is difficult to be definitive about preference structure from a limited number of choices: several explanations may be consistent with repeated selection of particular alternatives, including fully compensatory behaviour. 
EasyGreen energy allows you to choose a set dollar amount of renewable energy certificates (RECs) to be purchased on your behalf by Synergy

\section{Calculate the cost of EasyGreen}

Your contribution amount (per bill) $\$$

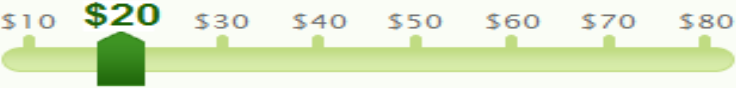

Based on average daily household consumption: 17.3 units

Number of billing days: 60
How will you help the environment?

Renewable energy certificates (RECs) representing an amount equal to approximately $35.34 \%$ of your electricity consumption will be purchased from nationally accredited GreenPower renewable energy sources.

Approximately 2.03 tonnes of $\mathrm{CO}_{2}$ will be saved each year

That can be compared to:

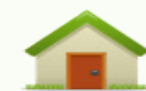

Powering 4.24 month

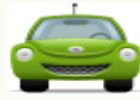

Removing 0.65 cars from our roads

Calculations based on a medium sized car benchmarked on a Toyota Camry 241

$8.9 \mathrm{~L} / 100 \mathrm{~km}$ travelling $15,000 \mathrm{~km}$ in a year.

QUICK These figures are based on the average daily household consumption figures included above. For TIP greater accuracy refer to your most recent bill for your actual household consumption levels.

3 Add EasyGreen to my account

My contribution amount (per bill): $\$ 20$ -

Figure 1: Synergy's Green Power Web Interface showing the EasyGreen tab 
If these were the only electricity products available, which product would you buy?

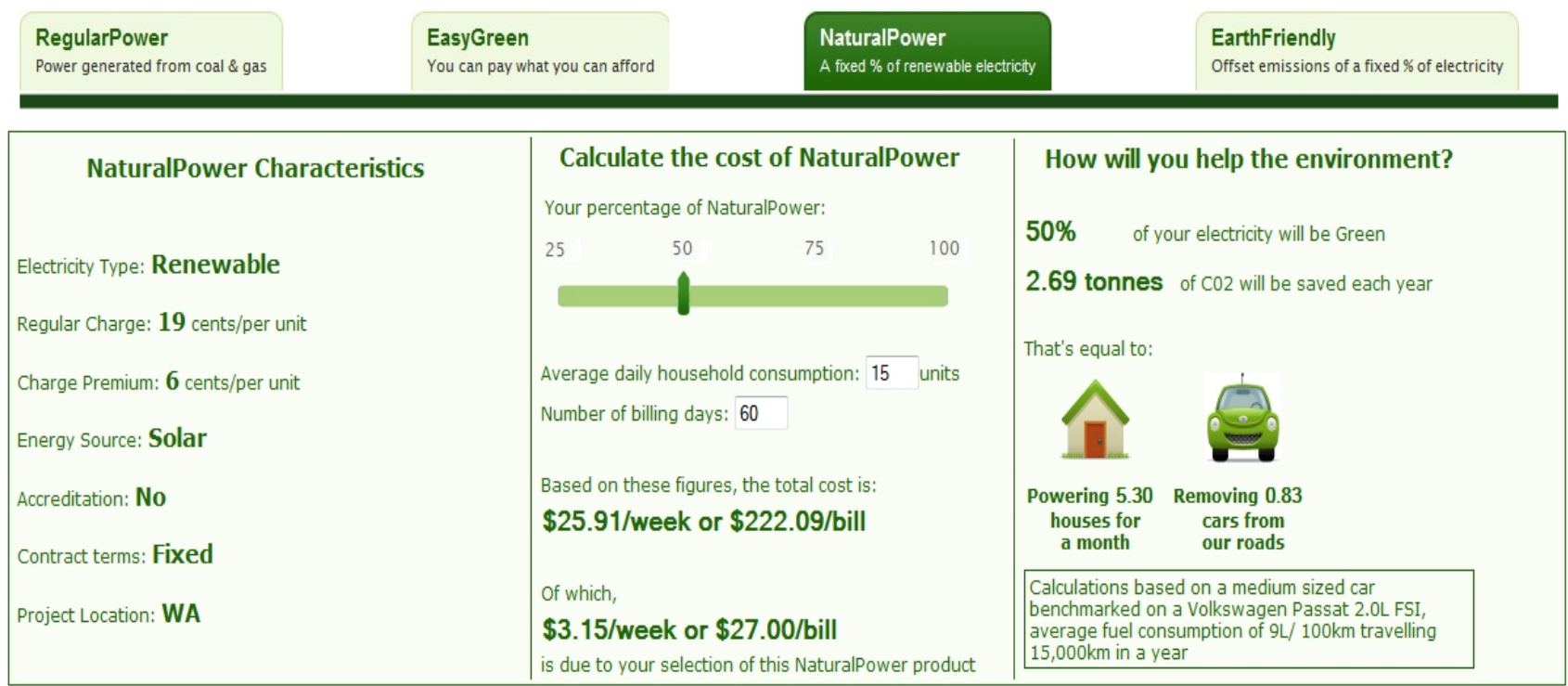

I choose NaturalPower, with a commitment of $50 \%$.

Please note that 'Easy Green', 'Natural Power' and 'Earth Friendly' are registered trademarks of Synergy. The use of these trademarks in this survey has been approved by Synergy. However, the products presented in this survey are only hypothetical and does not represent Synergy's existing green energy products.

\section{Figure 2: An Example of a Choice Set within the Modified Interface showing the Natural Power}

tab

Table 1 summarizes the attributes and associated values that are used to describe the products. These attributes and values are carefully chosen to capture the differences in existing green electricity products in the Australian market, but it should be noted that the type of source, accreditation, contract terms and location of renewable energy source are not attributes that are described as part of the actual Synergy products. The regular charge (which defines the cost of the conventional electricity, and provides the baseline costs for the green products, to which the elected contribution is added) is fixed within any choice set, but varies across choice sets. The implication is that this cannot be considered as a direct attribute to explain choices across products. However, we anticipate that the level of the regular charge 
(or more specifically, the expected total utility bill, which will also be influenced by average daily use) may influence the choice between conventional and green products. For example, if regular charge is high, leading to a high baseline bill, respondents may be less willing to commit to further expenditure. The appropriateness of the attributes and associated value ranges were verified in a pilot study.

The design of the survey used an s-efficiency criteria (Scarpa and Rose, 2008) using the Ngene software (Rose and Bliemer), with 12 choice sets, blocked into 2 groups of 6 . Priors for the design were derived from a small pilot study. For the 6 choice sets each respondent saw, there was a different regular charge (which was common to all alternatives within the choice set, and hence not used in the design itself). These progressively increased in value (from 19 to 29) through the design for half of the sample, while they declined for the other half (29 through 19). After the 6 design questions, the $7^{\text {th }}$ repeat preference check question (with zero premium) was asked. The online survey was conducted through Pureprofile ${ }^{5}$ in June of 2012, with 831 completed responses. The recruitment was constrained to the Metropolitan Perth area which is served by the Synergy electricity network. We then provided Pureprofile with relevant age and gender distributions from 2011 Australian Census as screens to recruit a sample that is representative of the age and gender composition of the population in the area.

\footnotetext{
${ }^{5}$ Pureprofile is Australia's leading independent on-line research panel provider founded in 2000, maintaining a panel of 400,000 with 40,000 monthly active users within Australia.
} 
Table 1: Product Attributes and Attribute Values

\begin{tabular}{cc}
\hline Attributes & Attribute Values \\
\hline Regular Charge & $19,21,23,25,27,29$ \\
Charge Premium & $0,1,2,4,6$ \\
Energy Source & Coal \& Gas, Hydro, Bio, Wind, Solar \\
Accreditation & Yes, No \\
Contract Terms & Fixed (2-Year), Flexible \\
Location & WA, Non-WA \\
\hline
\end{tabular}

\section{Modeling Approach}

Consumer choice analysis has made extensive use of random utility models where the utility from option $\mathrm{j}$ for respondent $\mathrm{i}$ is given by

$$
U_{i j}=V_{i j}+\varepsilon_{\mathrm{ij}}
$$

The utility $U_{i j}$ consists of a systematic component $V_{i j}$ and a random disturbance $\varepsilon_{j i}$ Utility maximization implies that the probability that consumer $i$ will choose alternative $j, P_{i j}$, is determined by

$$
\operatorname{Prob}_{i j}=\operatorname{Prob}\left(U_{i j}>U_{i k}\right) \quad \forall k \neq j
$$

The probability can be estimated empirically once the specification of the deterministic component $V_{i j}$ and the characteristics of the stochastic component $\varepsilon_{j i}$ are known. A large number of choice analyses have focused on multinomial or conditional logit models where the stochastic disturbance is assumed to be independently and identically distributed (IID) with a Gumbel distribution. The IID assumption has an important behavioral association with a property known as the Independence of Irrelevant Alternatives (IIA) which states that the ratio of the choice probabilities of any pair of alternatives is 
independent of the presence or absence of any other alternative in a choice set. An important behavioral implication of IIA is that any pair of alternatives (choices) are equally similar or dissimilar (Hensher et al., 2005). In our choice setting where households need to choose among different electricity products as well as different commitment levels, it is very likely that the IIA/IID assumption is violated if some commitment levels are perceived as closer substitutes. For instance, entry-level commitments (or toplevel commitments) may be viewed as closer substitutes than intermediate commitment levels. The assumption is also violated if households perceive commitment levels for the same product are closer substitutes when compared to commitment levels for a different product.

If there is unobserved correlation among alternatives, multinomial or conditional logit models will generate inconsistent parameter estimates. We relax the IIA assumption and estimate an error component multinomial (ECM) logit model. The random utility specification is accordingly modified as follows:

$$
U_{i j}=\boldsymbol{\beta}^{\prime} \boldsymbol{x}_{i j}+\theta_{j} \mathrm{EC}_{i j}+\varepsilon_{i j}, j=1, \ldots, 17
$$

where $\boldsymbol{x}$ refers to the vector of variables that enter into utility functions. The 17 alternatives correspond to conventional power $(j=1), 8$ commitment levels for EasyGreen $(j=2, \ldots, 9)$, and 4 commitment levels for each of NaturalPower $(j=10, \ldots, 13)$ and EarthFriendly $(j=14, \ldots, 17)$. The random disturbances $\varepsilon_{\mathrm{ij}}$ are IID Gumbel distributed. The error components $\mathrm{EC}_{\mathrm{ij}}$ are alternative specific random individual effects that account for choice situation variation that is unobserved and not accounted for by the other model components. The error component has zero mean and unit variance, so the parameter $\theta_{\mathrm{j}}$ is the standard deviation.

The ECM specification resembles a random effects model for panel data. The conditional probability for the choice of commitment level $j$ under the IID assumption on $\varepsilon_{\mathrm{ij}}$ is: 


$$
\operatorname{Prob}\left(y_{i}=j \mid \mathbf{E C}_{\boldsymbol{i q}}\right)=\exp \left(\boldsymbol{\beta}^{\prime} \boldsymbol{x}_{i j}+\theta_{q} \mathrm{EC}_{i q}\right) / \sum_{j=1}^{17} \exp \left(\boldsymbol{\beta}^{\prime} \boldsymbol{x}_{i j}+\theta_{q} \mathrm{EC}_{i q}\right)
$$

where $q=$ Conventional, EasyGreen, NaturalPower, EarthFriendly, Minimum, Maximum, and where $y_{i}$ is the index of the choice made. Parameters can then be estimated using the method of maximum simulated likelihood. The individual random "error components" do not need to be alternative specific. These error components can be rearranged to capture correlation across alternatives such that utility functions of correlated alternatives may share a common error component. Based on our priors of where correlation may be present, we have assumed that the vector of $\mathbf{E C}_{\boldsymbol{i q}}$ includes the following six error components (we omit the respondent subscript $\imath$ ):

1) $\mathrm{EC}_{\text {Conventional }}$ for conventional electricity $(j=1)$;

2) $\mathrm{EC}_{\text {EasyGreen }}$ for all commitment levels of EasyGreen $(j=2, \ldots, 9)$;

3) $\mathrm{EC}_{\text {NaturalPower }}$ for all commitment levels of NaturalPower $(j=10, \ldots, 13)$;

4) $\mathrm{EC}_{\text {EarthFriendly }}$ for all commitment levels of EarthFriendly $(j=14, \ldots, 17)$;

5) $\mathrm{EC}_{\text {Minimum }}$ for all minimum commitment levels - that is $\$ 10,25 \%$, and $25 \%$ for EasyGreen, NaturalPower and EarthFriendly respectively $(j=2,10,14)$;

6) $\mathrm{EC}_{\text {Maximum }}$ for all maximum commitment levels - that is $\$ 80,100 \%, 100 \%$ for EasyGreen, NaturalPower and EarthFriendly $(j=9,13,17)$.

We check the order condition and the rank condition of the proposed ECM using the tests provided in Walker et al. (2007) to make sure the model is identified. A detailed discussion of these conditions is provided in the Appendix A.

We define utility at the lowest level, i.e. at the commitment level, but assume that there are some cross utility function parameter restrictions e.g. that the effect of a green product characteristic has the same 
effect on utility derived from all commitment levels of that product. We assume that utility of conventional depends on the total cost, and individual attributes. The utilities for the commitment levels of each of the green products depends on the attributes of the product, and the total cost and carbon emission savings at each of the commitment levels. As the premium level differs across products, there is not a collinear relationship between costs and emissions within the alternatives of a choice set (the lower the premium, the higher the emissions savings for any particular level of total cost). An alternative specific constant is introduced for each of the commitment levels of all three green products. Green product attributes are effects coded and other variables are described in Table 2. An explicit statement of the utility equations is given in the Appendix B. 
Table 2 - Variable Definitions

\begin{tabular}{|c|c|}
\hline Variables & Definition \\
\hline TotalCost & $\begin{array}{l}\text { Total cost of the household's average bill on a } 60 \text {-day billing cycle }(\$) \text { (including } \\
\text { the green contribution if any) }\end{array}$ \\
\hline Carbon & Annual carbon savings (tones of CO2) \\
\hline Female & 1 for female head of household, else 0 . \\
\hline Age & Age of respondents (years) \\
\hline HighSchool & $\begin{array}{l}1 \text { if the respondent's highest education level attained is high school; the default } \\
\text { (0) is primary school }\end{array}$ \\
\hline TertiaryUnder & $\begin{array}{l}1 \text { if the respondent's highest education level attained is tertiary undergraduate; } \\
\text { the default }(0) \text { is primary school }\end{array}$ \\
\hline TertiaryPost & $\begin{array}{l}1 \text { if the respondent's highest education level attained is tertiary postgraduate; the } \\
\text { default }(0) \text { is primary school }\end{array}$ \\
\hline TradeTAFE & $\begin{array}{l}1 \text { if the respondent's highest education level attained is Trade or TAFE; the } \\
\text { default (0) is primary school }\end{array}$ \\
\hline ClimateNo & $\begin{array}{l}1 \text { if the respondent answers - "No" - to the question "Do you believe that } \\
\text { climate change is occurring"; the default }(0) \text { is "Yes" }\end{array}$ \\
\hline ClimateUnsure & $\begin{array}{l}1 \text { if the respondent answers - "I'm not sure" - to the question "Do you believe } \\
\text { that climate change is occurring"; the default (0) is "Yes" }\end{array}$ \\
\hline GreenParty & $\begin{array}{l}1 \text { if the respondent chooses to vote for the Green Party in the next federal } \\
\text { election, else } 0 .\end{array}$ \\
\hline TrustUt & $\begin{array}{l}\text { Likert scale (1-5): "How trustworthy do you think utility companies are?", with } 5 \\
\text { associated with the highest level of trust }\end{array}$ \\
\hline TrustGov & $\begin{array}{l}\text { Likert scale (1-5): "How trustworthy do you think the government's } \\
\text { accreditation and annual auditing of green electricity products is?", with } 5 \\
\text { associated with the highest level of trust }\end{array}$ \\
\hline Carbon & Tonnes of carbon saved each year \\
\hline Accreditation ${ }^{*}$ & $\begin{array}{l}1 \text { for products accredited by the National GreenPower Accreditation Program, } \\
\text { otherwise }=-1\end{array}$ \\
\hline Contract $^{*}$ & 1 if the electricity contract is fixed ( 2 years), otherwise $=-1$ \\
\hline Location $^{*}$ & 1 if renewable or offset projects are located in Western Australia, otherwise $=-1$ \\
\hline Hydro* & 1 if energy source is hydro; the default (-1) is bio-energy \\
\hline Solar ${ }^{*}$ & 1 if energy source is solar; the default $(-1)$ is bio-energy \\
\hline Wind $^{*}$ & 1 if energy source is wind; the default (-1) is bio-energy \\
\hline
\end{tabular}

${ }^{*}$ Green products attributes are effects coded.

Although not reported below, we have also investigated whether there are any effects of the level of the regular charge (beyond the implications for total cost) on choices. Because the regular charge is constant across all alternatives we do this by introducing it as a factor that may affect only the utility of 
the conventional electricity choice. Our prior hypothesis was that a higher regular charge may crowd out the green products (even if, relatively, costs of all products will be increased). We did not find any evidence of this effect.

\section{Results}

We first identified those respondents that may have non-compensatory repeat preferences or serial nonparticipation (von Haefen et al., 2005). A respondent is classified as a "repeat conventional" consumer if she/he chooses conventional power in all seven choice questions. Such choice suggests that the respondent is not responsive to any variations in attribute values. We have identified 118 such respondents out of a total of 831 sampled respondents. A logit regression, where the dependent variable is a dummy which takes the value of one if a respondent chooses conventional power in all seven questions, shows that customers who believe that climate change is not occurring, those who would not vote for the Green Party, and those who have lower level of trust in government are more likely to have repeat preference for conventional power (Table 3). On the other hand, females with higher educational levels are more likely to participate in GreenPower programs. This is also consistent with recent revealed-preference studies (Conte and Jacobsen, 2014).

We have also identified 269 (out of 831) "repeat green" consumers who always choose green power products in all seven questions. Recorded response time for completing each choice question reveals pronounced behavioral differences between "repeat conventional" respondents and "others" but no significant differences between "repeat green" respondents and "others". As shown in Figure 3, response time dropped significantly after the first choice question being answered in all three groups of respondents; however, respondents having "repeat conventional" preferences - that is, choosing 
conventional power in all seven questions, spent significantly shorter time on each choice question than those from the other two groups. In addition, the average response time increased substantially for the "others" group and the "repeat green" group when the setting of the choice task was changed from a four-option choice to a three-option choice in the final repeat preference check. The implication is that although the "repeat green" respondents are not selecting the conventional electricity option they do appear to be considering the options available to them throughout the survey. However, the same behavioral response was not observed for the "repeat conventional" group. In what follows, we only report results from models in which the "repeat conventional" respondents are removed. However, we have also estimated models using the full sample and results are available in the Supplementary Material.

Table 3 - Results from Logit Regression ${ }^{\dagger}$

\begin{tabular}{lllll}
\hline Attributes & Coefficient $^{\text {tt }}$ & Z-stat. & Lower 95\% & Upper 95\% \\
\hline Female & $-0.614^{* *}$ & -2.89 & -1.031 & -0.197 \\
Age & 0.008 & 1.11 & -0.006 & 0.023 \\
HighSchool & $-1.883^{*}$ & -2.09 & -3.651 & -0.115 \\
TertiaryUnder & $-2.541^{* *}$ & -2.80 & -4.321 & --0.761 \\
TertiaryPost & $-3.101^{* *}$ & -3.24 & -4.980 & -1.223 \\
TradeTAFE & $-2.201^{*}$ & -2.43 & -3.977 & -0.426 \\
ClimateNo & $0.971^{* *}$ & 3.05 & 0.348 & 1.595 \\
ClimateUnsure & 0.486 & 1.92 & -0.011 & 0.983 \\
GreenParty & $-1.308^{*}$ & -2.05 & -2.558 & -0.059 \\
TrustUt & 0.071 & 0.57 & -0.176 & 0.319 \\
TrustGov & $-0.410^{* *}$ & -3.10 & -0.669 & -0.150 \\
Constant & 1.037 & 1.06 & -0.872 & 2.947 \\
\hline
\end{tabular}

Chi squared(11) $74.73^{* *}$

Number of obs. 831

†We do not include income as not all respondents disclose their income information; however, regression using income-restricted sample produce similar results; ${ }^{\dagger * *}$ and $*$ denotes significance level at $1 \%$ and $5 \%$. 


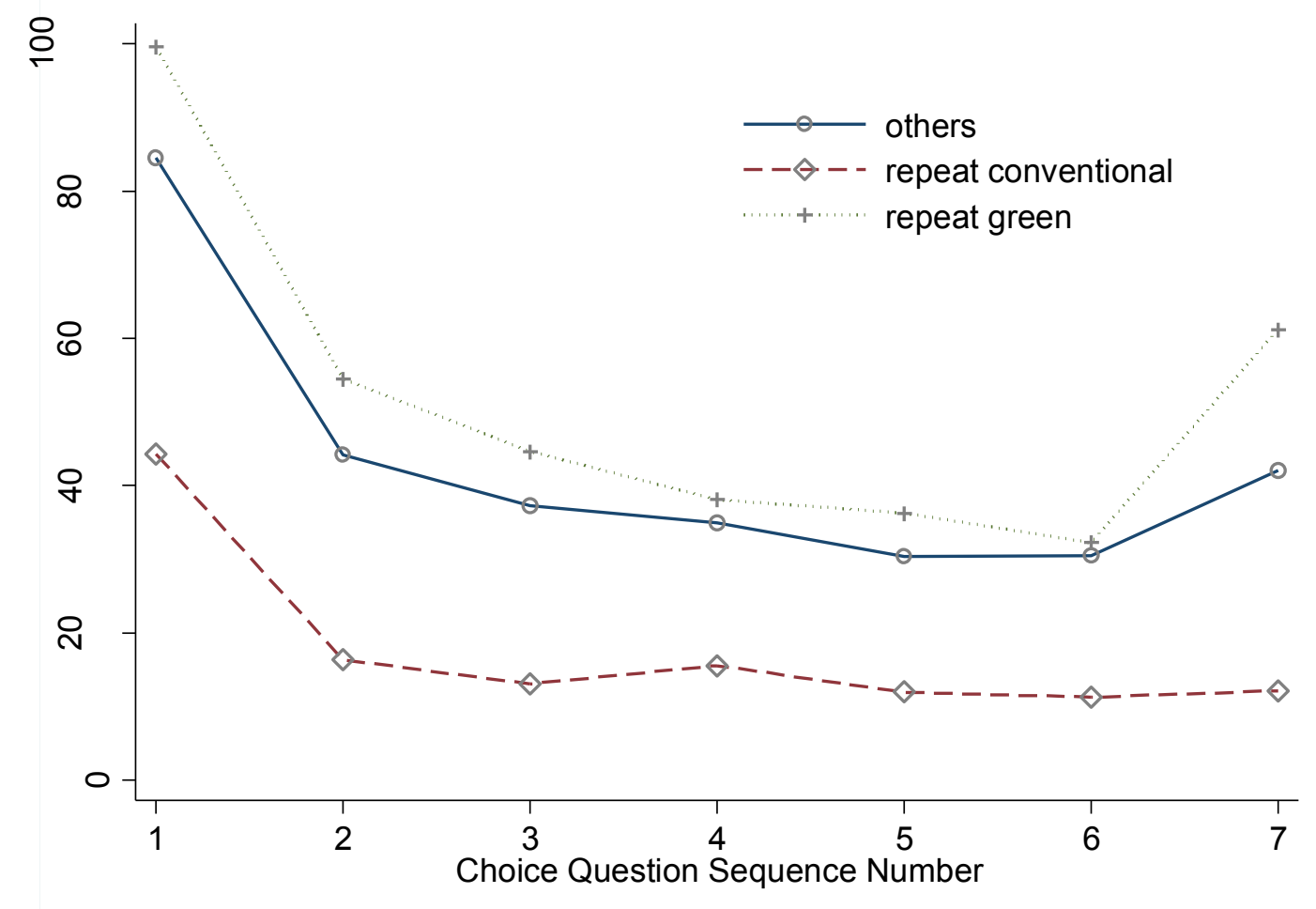

Figure 3: Average Time Spent on Each Choice Question (Seconds)

Although we aimed to recruit a sample that is representative of the age and gender distributions in Western Australia according to Australia's 2011 Census, applying these screens significantly restricted the size of the sample that could be recruited. At later stage of the recruiting process, we removed age and gender screens but kept the location screen. This resulted in higher proportion of female respondents in our full sample and restricted sample $(60.3 \%$ and $62.7 \%)$ than that in the entire population in Western Australia (49.7\%). Our full sample and restricted sample also have higher proportion of respondents that have bachelor or higher degrees $(45.3 \%$ and $48.3 \%)$ than the entire population. Table 4 presents summary statistics for the full sample and the restricted-sample with "repeat conventional" respondents removed. 
Table 4 - Summary Statistics

\begin{tabular}{|c|c|c|c|c|c|c|}
\hline \multirow{2}{*}{ Variable } & \multicolumn{2}{|c|}{$\begin{array}{l}\text { Full Sample }{ }^{\dagger}(\text { N. of } \\
\text { Obs. }=831)\end{array}$} & \multicolumn{2}{|c|}{${ }_{\text {Restricted Samplett }}^{\text {tt }}$ (N. of Obs. $=$} & \multirow[t]{2}{*}{ Max } & \multirow[t]{2}{*}{ Min } \\
\hline & Mean & S.D. & Mean & S.D. & & \\
\hline Female & 0.603 & 0.490 & 0.627 & 0.484 & 1 & 0 \\
\hline Age & 44.30 & 14.06 & 43.76 & 13.88 & $82^{\dagger} / 80^{\dagger t}$ & 20 \\
\hline HighSchool & 0.286 & 0.452 & 0.268 & 0.443 & 1 & 0 \\
\hline TertiaryUnder & 0.298 & 0.458 & 0.313 & 0.464 & 1 & 0 \\
\hline TertiaryPost & 0.155 & 0.362 & 0.170 & 0.376 & 1 & 0 \\
\hline TradeTAFE & 0.252 & 0.434 & 0.245 & 0.431 & 1 & 0 \\
\hline ClimateNo & 0.076 & 0.265 & 0.06 & 0.238 & 1 & 0 \\
\hline ClimateUnsure & 0.176 & 0.381 & 0.164 & 0.371 & 1 & 0 \\
\hline GreenParty & 0.094 & 0.292 & 0.105 & 0.307 & 1 & 0 \\
\hline TrustUt & 2.543 & 0.986 & 2.568 & 0.984 & 5 & 1 \\
\hline TrustGov & 2.471 & 1.001 & 2.537 & 1.002 & 5 & 1 \\
\hline
\end{tabular}

${ }^{\dagger}$ Full sample; ${ }^{\text {tt}}$ Restricted sample with "repeat conventional" respondents removed.

We have estimated choice models with and without attitudinal variables (ClimateNo, ClimateUnsure, GreenParty, TrustUt and TrustGov). Adding self-reported attitudinal variables in to the utility function is likely to introduce measurement error and endogeneity because the same unobservable factors driving responses to the attitudinal questions are also likely to drive responses to the choice scenarios (Hess and Hensher, 2013). Table 5 presents our results from an Error Components Multinomial Logit model without attitudinal variables. Results from models including these attitudinal variables are provided in the Supplementary Material. Our general conclusions do not change.

We have compared models with different structures of error components (EC): 1) no ECs; 2) four product specific $\left.\mathrm{ECs}\left(\mathrm{EC}_{\text {Conventional }}, \mathrm{EC}_{\text {EasyGreen }}, \mathrm{EC}_{\text {NaturalPower, and }} \mathrm{EC}_{\text {EarthFriendly }}\right) ; 3\right)$ four product-specific ECs and one EC for entry commitment levels $\left(\mathrm{EC}_{\text {Minimum }}\right)$; 4) four product-specific $\mathrm{EC}$, one $\mathrm{EC}$ for entry commitment levels and one $\mathrm{EC}$ for maximum commitment levels $\left(\mathrm{EC}_{\text {Maximum }}\right)$. Likelihood ratio (LR) tests have rejected the models with more parsimonious error structures, leaving us with error structure 4): the complete set of error components. As shown in Table 5, all ECs are highly significant. Our model is estimated using maximum simulated likelihood with Halton draws. Researchers 
differ in the appropriate number of draws used in the replications. However, generally speaking, the more complex the model is, and the greater the number of random parameters in it, the larger will be the number of draws required to stabilize the estimates. Train (2009) recommends several hundreds. We have a relatively complex model with 17 alternatives and six random parameters. We have experimented with different numbers of draws and found that model estimates converge at roughly 800 draws. Our final model is estimated in Stata 13 using the mixlogit package with 800 Halton draws.

Most variables are significant with expected signs. Female customers are more likely to choose green electricity products. Education attainment and age are statistically insignificant and a likelihood ratio test shows that removing these variables has no significant impact on the model ( $p$ value $=0.985)$. This may seem to contradict other published findings: Conte and Jacobsen (2014) find that the education of the consumer base is one of the key determinants the participation rate in green electricity programs. This is confirmed by the results shown in Table 3 where we show educational levels are negatively associated the repeat choice of conventional power. This suggests that education plays a significant role in converting consumers with repeat preference for conventional power to possible participants of green electricity programs but not in the choice among products once they become "possible" participants. This important insight can not be identified in studies examining utility-level average consumer behavior (Conte and Jacobsen). We report the results from alternative model specifications in Table 10 - Table 13 in the Supplementary Material.

Among different green electricity products, people favor products that have been accredited by the NGPAP. Flexible contract terms are preferred. People would like renewable energy projects or carbon offset projects to be located in WA. Among all renewable energy sources, only solar is differentially favored, which is possibly a reflection of the high penetration of solar panels in the Australian 
residential sector as well as high solar awareness due to frequent media exposure and public and private campaigns. This could also due to the negative externalities (e.g. ecosystem services, biodiversity conservation and air quality) associated with hydro, wind and bio-energy often discussed in public media.

We have tested the hypotheses that the three product-specific ASCs are equal. LR tests have rejected this equality constraint with a p-value less than 0.001. Our final model thus includes different ASCs for the green products. The significantly positive coefficient on carbon shows that consumers do derive utility from contributing to the environmental good which captures the part of the warm glow effect that increases with contribution levels. The entry-level ASC (ASCMinimum) is very significant and positive, implying that consumers strongly favor the entry level even after controlling for cost and carbon saved. That is - consumers have chosen the minimum commitment levels not simply because they cost less. We interpret this as an indication of a strong buy-in warm glow effect, and reflected in the raw data by the fact that, in cases where a green electricity product is chosen, over 60 percent have selected the minimum commitment levels - that is, $\$ 10$ for EasyGreen, 25\% for Natural Power and 25\% for EarthFriendly. We also compare this finding with market data later. 
Table 5 - Results from Error Component Model (ECM)

\begin{tabular}{|c|c|c|c|c|}
\hline Attributes & $\begin{array}{r}\text { Coefficient } \\
+\end{array}$ & Z-stat. & $\begin{array}{r}\text { Lower } \\
95 \% \\
\end{array}$ & Upper $95 \%$ \\
\hline \multicolumn{5}{|l|}{ Common to all alternatives } \\
\hline TotalCost & $-0.082^{* *}$ & -19.48 & -0.090 & -0.074 \\
\hline \multicolumn{5}{|l|}{ Specific to conventional } \\
\hline Female & $-0.754^{*}$ & -2.43 & -1.363 & -0.145 \\
\hline \multicolumn{5}{|l|}{ Specific to green products } \\
\hline Carbon & $0.040 * *$ & 4.18 & 0.021 & 0.059 \\
\hline Accreditation & $0.221 * *$ & 8.55 & 0.170 & 0.272 \\
\hline Contract & $-0.195^{* *}$ & -7.10 & -0.249 & -0.141 \\
\hline Location & $0.258 * *$ & 9.55 & 0.205 & 0.311 \\
\hline Hydro & 0.029 & 0.63 & -0.060 & 0.117 \\
\hline Solar & $0.126^{* *}$ & 2.80 & 0.038 & 0.215 \\
\hline Wind & 0.027 & 0.62 & -0.059 & 0.113 \\
\hline ASCEasyGreen & $-2.175^{* *}$ & -7.76 & -2.725 & -1.626 \\
\hline ASCNaturalPower & $-1.857^{*}$ & -7.07 & -2.372 & -1.342 \\
\hline ASCEarthFriendly & $-2.370 * *$ & -9.07 & -2.883 & -1.858 \\
\hline ASCMinimum & $1.549^{* *}$ & 11.40 & 1.283 & 1.815 \\
\hline ASCMaximum & $-0.993 * *$ & -3.47 & -1.555 & -0.432 \\
\hline \multicolumn{5}{|l|}{ Error Components } \\
\hline ECConventional & $3.273^{* *}$ & 17.35 & 2.904 & 3.643 \\
\hline ECEasyGreen & $1.686^{* *}$ & 14.87 & 1.463 & 1.908 \\
\hline ECNaturalPower & 0.309 & 1.32 & -0.149 & 0.766 \\
\hline ECEarthFriendly & $1.249 * *$ & 11.65 & 1.039 & 1.459 \\
\hline ECMinimum & $2.721 * *$ & 17.84 & 2.422 & 3.020 \\
\hline ECMaximum & $-2.949 * *$ & -11.87 & -3.436 & -2.462 \\
\hline Maximized log likelihood (LL) & \multicolumn{4}{|c|}{-6847.4306} \\
\hline Wald chi squared & \multicolumn{4}{|c|}{$1304.58^{* *}$} \\
\hline Number of obs. & \multicolumn{4}{|c|}{72726} \\
\hline
\end{tabular}

\section{LL for Alternative} Specifications

LL with common product ASC ${ }^{\dagger t}$ $-6877.3222$

LL without ASCMaximum $-7084.9093$

LL with product ASCs only $-7868.795$

LL without error components $-8492.6333$ LL with constants only $-9108.3619$

$\overline{\dagger * *}$ and $*$ denotes significance level at $1 \%$ and $5 \%$; "Imposing restrictions that ASCEasy Green, ASCNaturalPower and ASCEartbFriendly are all equal. 
Table 6 - Direct and Cross Marginal Effects of a Change in a Product Attribute and Individual Characteristics on the Probability of Choice at Product ${ }^{\S}$ Level

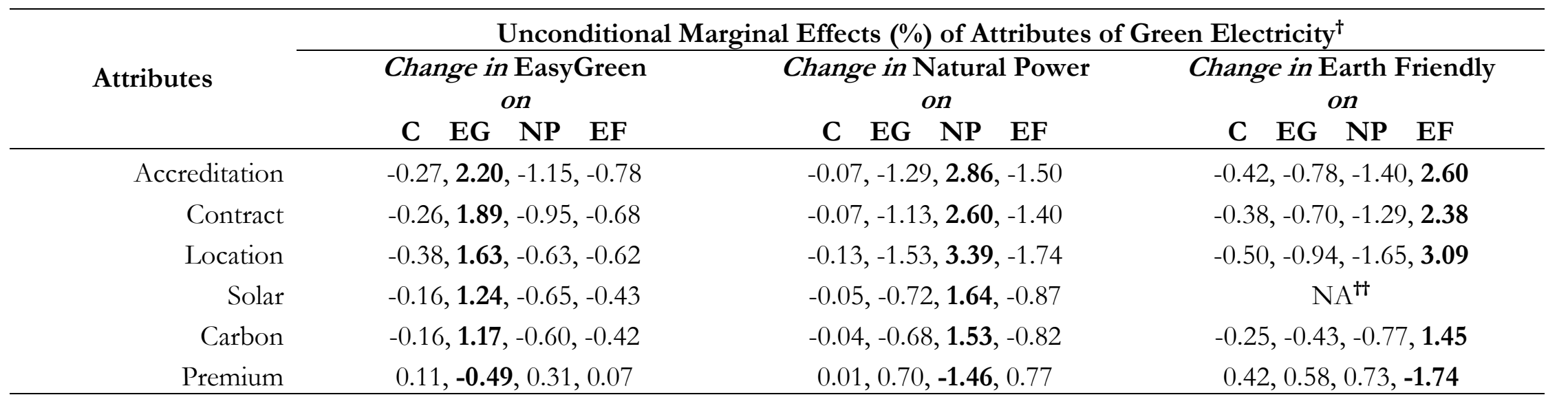

Unconditional Marginal Effects (\%) of Personal Characteristics

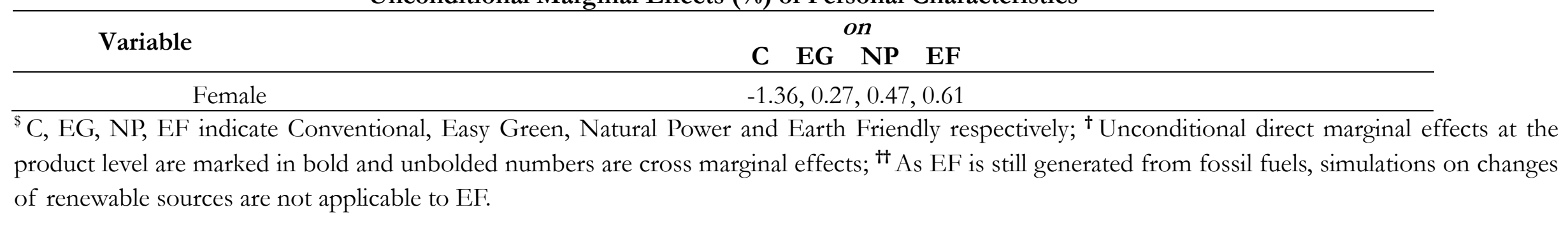


Table 7 - Unconditional Marginal Effects of a Simultaneous Change in Green Product Attribute Values across all Products on Probability of Selecting Green Products

\begin{tabular}{|c|c|c|c|c|}
\hline \multirow{2}{*}{ Attribute Values } & \multicolumn{4}{|c|}{ Unconditional Marginal Effects (\%) } \\
\hline & Green Total ${ }^{\dagger}$ & EasyGreen & NaturalPower & EarthFriendly \\
\hline Accredited & 0.79 & 0.12 & 0.30 & 0.37 \\
\hline Flexible Contract & 0.70 & 0.11 & 0.26 & 0.33 \\
\hline Local Projects & 0.93 & 0.14 & 0.35 & 0.44 \\
\hline Solar ${ }^{\text {t† }}$ (vs. Bio) & 0.21 & 0.52 & 0.99 & -1.30 \\
\hline Carbon & 0.43 & 0.07 & 0.16 & 0.20 \\
\hline ttt'Total & 3.19 & 0.91 & 2.38 & -0.11 \\
\hline \multicolumn{5}{|c|}{$\begin{array}{l}\text { † "Green Total" provides marginal effects on the Green nest of a generic value change; "t } \\
\text { Simulation based on a generic value change to EG and NP; "tt "Total" gives marginal effects of } \\
\text { simultaneous changes for all four green attributes from the baseline value i.e. of shifting from } \\
\text { "non-local, non-accredited, bio energy, zero carbon reduction with a fixed } 2 \text {-year contract" to } \\
\text { "local, accredited, solar energy, complete carbon reduction with a flexible contract" }\end{array}$} \\
\hline \multicolumn{5}{|c|}{ Table 8 - Conditional Marginal Effects (\%) of Premium on Commitment Levels } \\
\hline \multicolumn{2}{|c|}{ EasyGreen } & \multicolumn{3}{|c|}{ NaturalPower } \\
\hline Commitment Levels & Marginal Effects & Com & ent Levels & Marginal Effects \\
\hline & & & & 0.75 \\
\hline$\$ 10$ & 1.21 & & & 0.47 \\
\hline$\$ 20$ & 0.88 & & & -0.92 \\
\hline$\$ 30$ & 0.03 & & $\%$ & -0.30 \\
\hline$\$ 40$ & -0.25 & \multicolumn{3}{|c|}{ EarthFriendly } \\
\hline$\$ 50$ & -0.28 & Com & ent Levels & Marginal Effects \\
\hline$\$ 60$ & -0.24 & & & 0.75 \\
\hline$\$ 70$ & -0.18 & & $\%$ & 0.47 \\
\hline \multirow[t]{2}{*}{$\$ 80$} & -1.16 & & $\%$ & -0.92 \\
\hline & & & $\%$ & -0.30 \\
\hline
\end{tabular}

Table 9 - Conditional Marginal Effects (\%) of Buy-in Warm Glow on Commitment Levels

\begin{tabular}{cc|cc}
\hline \multicolumn{2}{c|}{ EasyGreen } & \multicolumn{2}{c}{ NaturalPower } \\
\hline Commitment Levels & Marginal Effects & Commitment Levels & Marginal Effects \\
\hline \multirow{3}{*}{$\$ 10$} & 9.69 & $25 \%$ & 9.61 \\
$\$ 20$ & -2.51 & $50 \%$ & -2.30 \\
$\$ 30$ & -1.32 & $75 \%$ & -3.16 \\
$\$ 40$ & -0.71 & $100 \%$ & -4.15 \\
\cline { 2 - 4 }$\$ 50$ & -0.39 & \multicolumn{2}{|c}{ EarthFriendly } \\
\cline { 2 - 4 }$\$ 60$ & -0.21 & Commitment Levels & Marginal Effects \\
\cline { 2 - 4 }$\$ 70$ & -0.12 & $25 \%$ & -61 \\
$\$ 80$ & -4.42 & $50 \%$ & -2.30 \\
\end{tabular}


Using the fitted ECM, we have simulated unconditional and conditional direct and cross marginal effects of changes in attributes' values and individual characteristics. As suggested by Louviere et al. (2000) we use the probability weighted sample enumeration (PWSE) rather than sample average or "naïve pooling" to simulate these marginal effects. Choice probabilities are calculated using the posterior individual-specific parameters (Train, 2009). Table 6 provides unconditional direct and cross marginal effects of attributes of interest. Unconditional direct marginal effects represent the change in the unconditional choice probability for an alternative given a 1-unit change in an attribute of interest for the same alternative, ceteris paribus, while for effects coded bivariate attributes (Accreditation, Contract, Location and Solar), this means a change of value from negative one to positive one. For the carbon attribute, we define the marginal change as one from zero reduction to complete reduction of total carbon emission from electricity consumption by a representative household (i.e. 6 tonnes) ${ }^{6}$. Unconditional cross marginal effects represent the impact that a 1-unit change in an attribute of interest to one alternative has upon the unconditional choice probabilities of competing alternatives, ceteris paribus. Direct and cross marginal effects for each product and each attribute sum to unity (allowing for rounding errors). The baselines for the six simulation scenarios are no accreditation, a 2-year fixed term contract, non-local projects, bio energy, current premium levels, and male respondents. The corresponding alternatives are accredited product, a flexible contract, local projects, solar energy, premium increased by 1 cent, and female respondents. As shown in the table, the impacts of product attributes on choice probabilities are small in absolute terms. However, given that average participation rate in GreenPower programs is only $1.14 \%$ in

\footnotetext{
${ }^{6}$ This is calculated assuming a representative Australian household with 18-unit consumption per day and a carbon intensity of electricity generation at 0.9 metric ton per megawatt hours in Western Australia.
} 
Australian utilities (Mewton and Cacho, 2011), these marginal effects are practically substantial.

Table 7 provides marginal effects for generic changes to all three green products in the value of a single green attribute as well as changes to all green attributes. This is to simulate the situation where a supplier changes the attributes of all the green products in their portfolio simultaneously. Changing all green attributes from the most unfavorable values to the most favorable values can increase the probability of selecting one of the three green products compared to conventional production increases by $2.74 \%$. Given the very low participation rate of green electricity programs in Australia, this suggests great potential for increasing participation by improving the design of GreenPower programs. The decomposition of this change across the three green products is $0.87 \%, 2.13 \%$ and $-0.27 \%$ for EasyGreen, NaturalPower and EarthFriendly respectively.

Table 8 reports the conditional (on the product being selected) marginal effect of a change in the premium on the level of commitment selected. Similarly, conditional marginal effects for each product should also sum to unity with only rounding errors. Increasing the premium makes the minimum commitment level more attractive (positive conditional marginal effect) compared to higher commitment levels (negative conditional marginal effect). However, this effect is very small if one considers that the maximum difference in premium in our experimental design is 6 cents (i.e. a 1 unit change represents a 17\% increase in premium): the probability of selecting the minimum commitment increases by only $1.21 \%, 0.75 \%$ and $0.75 \%$ for the green products for this change in premium, reflecting the lack of price sensitivity of commitment. This suggests that the (conditional) price elasticity of demand for green electricity within each product category is very low. This premium effect is also small if one compares it with the marginal 
effect of the buy-in warm glow reported in Table 9. This is the change in the probability of selecting a commitment level (conditional upon selecting the product) that is due to the minimum level ASC effect. This increases the probability of selecting the minimum commitment level by $9.69 \%, 9.61 \%$ and $9.61 \%$ respectively. It is clear that the buy-in warm glow effect, not the premium effect, dominates the consumer choices towards minimum commitment.

\section{Discussion}

It is of interest to compare our results with the market data for green electricity penetration. The actual premium for Synergy's green electricity products was 6.1 cent per unit at the time of the survey implementation. The electricity price was about 28-29 cents per unit (volume charge at 23 cents per unit, supply charge at roughly 2.5 cents per unit and a $10 \%$ GST). The participation rate in our survey for all choices with a 6-cent premium and a 29-cent regular charge is $4.1 \%$. This is higher than the average participation rate in green electricity programs observed in Australia which is slightly over 1\% (Mewton and Cacho, 2011). Despite our design effort to mimic the real market environment, the hypothetical nature of the experiment could result in higher participation rate. In addition, we provided respondents with additional attribute information that are not readily available to consumers in any single green electricity product in the market, which may contribute to the high participation rate observed in our experiment.. More importantly, the green products and the regular power are placed on an equal footing in the experimental design: each has a tab, and respondents are actively selecting across all 4 products. In the real market, regular power is the default, and consumers have to actively nominate in for green power via the web site. 
The NGPAP releases quarterly reports on each utility company's aggregated customer numbers and sales for accredited GreenPower products. As Synergy only has two accredited products - EasyGreen and NaturalPower, the reported statistics cover these two products only. We have discussed the low commitment level in Western Australia. However, compared with other states green power penetration at the commitment level in Western Australia is relatively high. Figure 4 shows the total number of green electricity customers and total green electricity sales in each state by quarter from 2004 to 2013. If we assume consumption for a representative household is 18-units per day, we can infer the average commitment level in each state, which is shown in Figure 5. Over time, commitment for subscribed green power customers in all states have converged to a low level ranging from $10 \%$ to $30 \%$ of total consumption. Considering that NGPAP has a compulsory requirement for a minimum 10\% commitment for all accredited GP products and some GP products may have a higher entry commitment level (e.g. $25 \%$ for NaturalPower), the observed market commitment levels (Figure 5) represent a strong consumer preference for minimum levels of commitment ${ }^{7}$. Our research shows that this preference is insensitive to premium changes. We interpret this as a strong indication of a buy-in warm glow effect.

\footnotetext{
${ }^{7}$ In an effort to mimick the actual market, we have chosen the same commitment levels that Synergy offers to the consumers; however, the outcome may be due to the fact that the commitment levels are spaced to far apart, a hypothesis not testable given the current experimental design. We thank one anonymous reviewer for providing this suggestion for future research.
} 

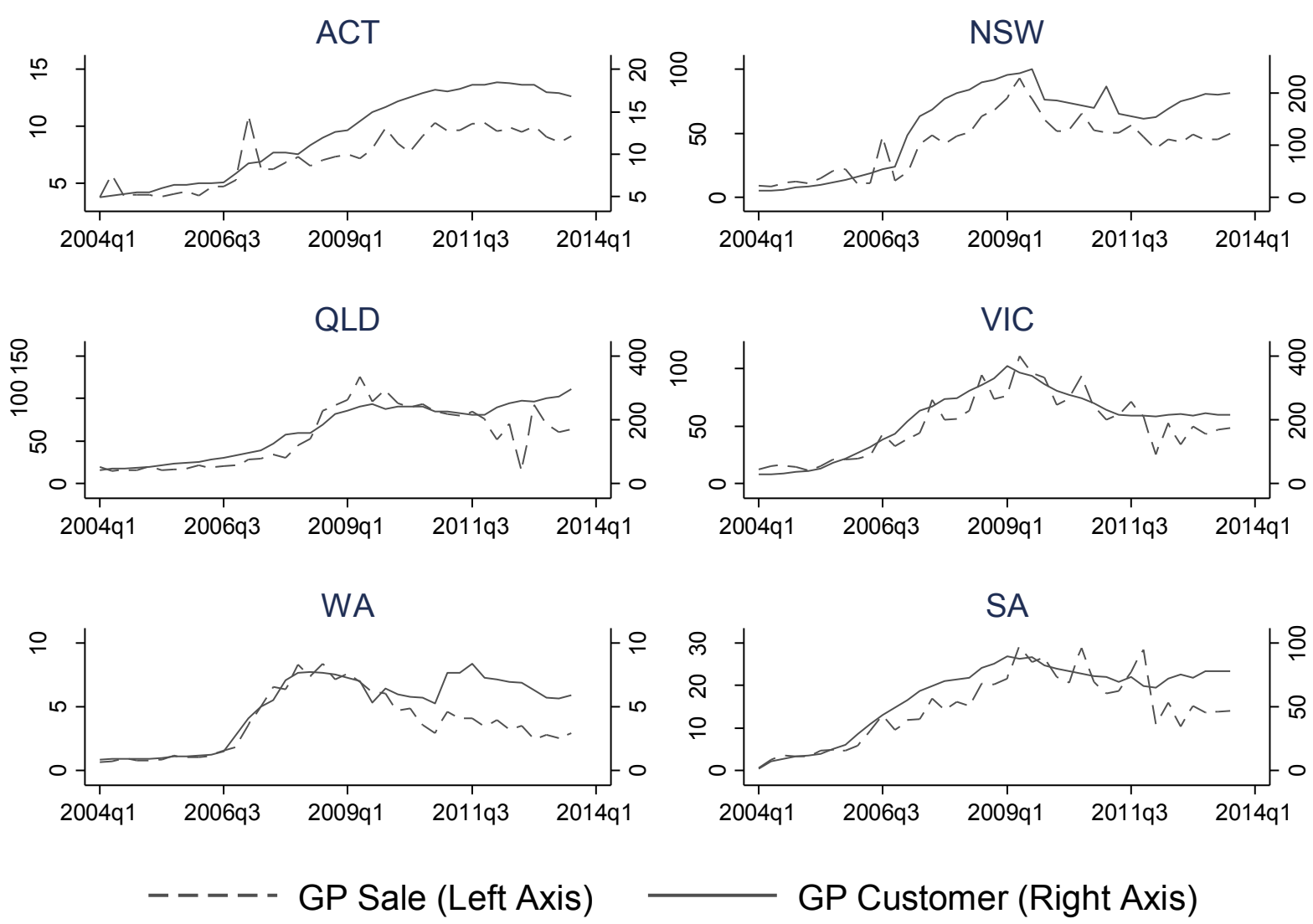

Figure 4: Residential Green Power Sales (GWH) and Customer Numbers ('000) 


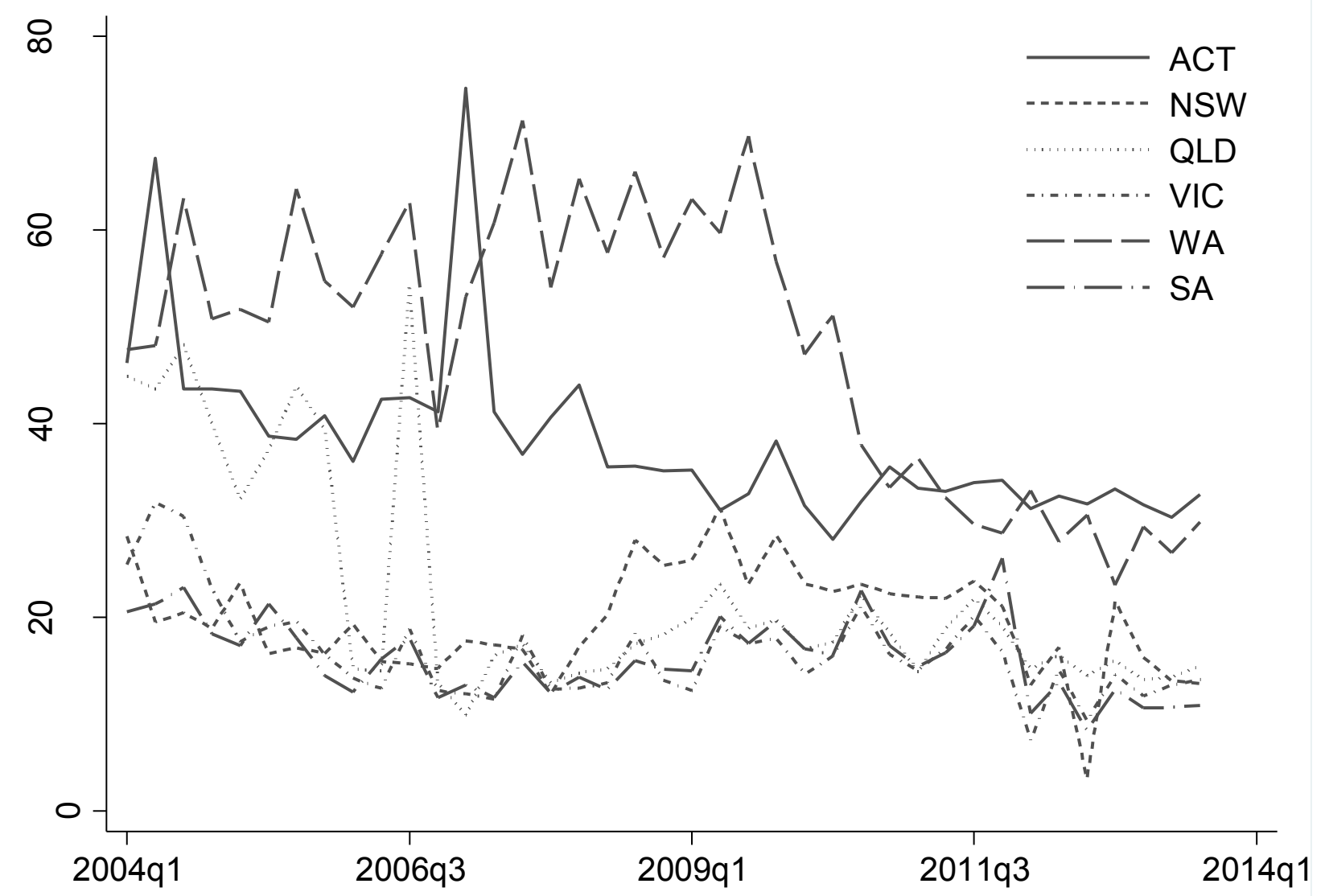

Figure 5: Inferred Average Residential Green Power Commitment Levels (\%)

Respondents are willing to pay $\$ .50$ per tonne of carbon emissions reduced. This is much lower than the price at the time the survey was conducted $\left(\$ 24.15 / \mathrm{t}^{8}\right)$ operating at the national level. It is also of interest to simulate the impact of the carbon tax on the demand of GP. The current carbon intensity of electricity generation in WA is roughly 0.84 ton per megawatt hours (ANGA, 2013). Given that the electricity in WA is mostly generated from fossil fuels, a carbon tax of that amount would increase the price of conventional electricity in WA by roughly $10 \%$. If we assume the cost of GP remains the same, our model predicts a $2.92 \%$ shift in market

\footnotetext{
${ }^{8}$ http:/ / www.cleanenergyregulator.gov.au/Carbon-Pricing-Mechanism/About-the-Mechanism/Fixed-Price-201215/Pages/default.aspx, retrieved 17 March, 2014. Note that the carbon tax on emissions in Australia was abolished in 2015.
} 
shares from conventional power to GP as a result. The decomposition of this growth in GP market share across the three green products is $0.75 \%, 0.92 \%$ and $1.26 \%$ for EasyGreen, NaturalPower and EarthFriendly respectively. This is a limited penetration for green electricity driven by consumers demand for the public good benefits. Moreover, because much of the new demand would still be for minimum commitment levels, the actual contribution to renewable energy generation is even more limited. In fact, the demand for green electricity in Western Australia decreased following the implementation of the carbon tax since the July of 2012 (Figure 4 and 5). Perino (2015) showed that voluntary environmental campaigns might run counter to intensions due to carbon leakage in regions with priced carbon reduction schemes that cover some but not all polluting industries. Observed demand reduction in voluntary programs is thus not necessarily detrimental to the overall emission reduction effort. However, this is not the case for GreenPower programs in Australia as generation from accredited GreenPower programs can directly offset the carbon reduction liabilities of conventional power. One explanation for the decline in demand following the implementation of a carbon tax may be that consumers might see contributions as less valuable when a mandatory policy is already in place, a response consistent with "moral licensing" (Harding and Rapson, 2013). In addition, Synergy spread the carbon cost over all consumers, including those purchasing green power who considered themselves already contributing to the reduction of carbon emissions.

\section{Conclusion}

This paper has made a number of contributions to understanding consumer preferences for green electricity products. The design has allowed us to evaluate not just the choice of product, 
but also the level of commitment (i.e. the quantity of green power) that consumers purchase. We do that within an Error Components Model that exploits the fact that commitment level in the real market is discrete, and hence there are limited numbers of levels that are open to consumers.

We find that the attributes of the green products themselves seems to have little impact on demand, although there are preferences for 'local' generation and solar power as the source of the renewable. Comparing Easy Green and Natural Power (where the only substantive difference in the products offered by Synergy is in the method of making the commitment: fixed contribution or $\%$ of bill), then Natural Power is the preferred product. At the level of commitment, respondents had a strong preference for the minimum commitment level available, and this is insensitive to the level of premium and associated cost. The high proportion of consumers who are selecting the minimum contribution is consistent with our interpretation of the commitment being largely made as 'warm glow', and with the results found elsewhere in the literature (i.e. Jacobsen et al 2012; Kotchen and Moore, 2008; Oberholzer-Gee, 2001) .

These results raise an interesting issue which we cannot address here: what would the consequences for choices be if the minimum levels were increased (e.g. from $\$ 10$ to $\$ 40$, or from $25 \%$ to $50 \%$ )? Would adoption of the green products remain at the current levels? If consumers are relatively less sensitive to premium and cost but more likely to choose the default minimum level, then a product design with a higher minimum level would contribute to greater environmental good. The fact that we observe low commitment levels across a whole range of GP products in all states provides some evidence that this is a generic pattern rather than an artifact of the specific characteristics of GP products considered in this study. A promising future research area would be to design a survey with different minimum commitment levels to 
examine the robustness of this conclusion. 


\section{Appendix A: Identification of ECM}

For the order condition, the number of estimable error parameters, $\mathrm{S}$, must adhere to: $\mathrm{S} \leq$ $\frac{J(J-1)}{2}-1$, where $J$ is the total number of alternatives. With $J=17$ in our case, the order condition can be easily met. To check the rank condition, we need to determine the covariance matrix of utility differences of the hypothesized model: $\Omega_{\Delta}$. For an illustration of the mapping from the covariance matrix of utility $\Omega$ to $\Omega_{\Delta}$, see Walker et al. (2007). The rank condition states that the number of estimable error parameters must adhere to: $\mathrm{S}=\operatorname{Rank}\left(\operatorname{Jacobian}\left(\operatorname{vecu}\left(\Omega_{\Delta}\right)\right)\right)-1$, where vecu is a function that vectorizes the unique elements of $\Omega_{\Delta}$ into a column vector. With our proposed error component structure, we have verified that $S=6$, which allows exact identification of all six error components.

\section{Appendix B: Utility functions}

Conventional

$$
\boldsymbol{U}_{\boldsymbol{j}=\mathbf{1}}=\alpha_{1} \text { TotalCost }+\varphi_{2} \text { Female }+\theta_{\text {Conventional }} \mathrm{EC}_{\text {Conventional }}+\varepsilon_{1}
$$

\section{Easy Green}

$$
\begin{aligned}
& \boldsymbol{U}_{\boldsymbol{j}=\mathbf{2}}=\text { ASCEasyGreen }+ \text { ASCMinimum }+\alpha_{1} \text { TotalCost }+\alpha_{2} \text { Carbon }+\alpha_{3} \text { Accreditation } \\
& \quad+\alpha_{4} \text { Contract }+\alpha_{5} \text { Location }+\alpha_{6} \text { Hydro }+\alpha_{7} \text { Solar }+\alpha_{8} \text { Wind } \\
& +\theta_{\text {Minimum }} \mathrm{EC}_{\text {Minimum }}+\theta_{\text {EasyGreen }} \text { EC }_{\text {EasyGreen }}+\varepsilon_{\mathrm{i}, 2} \\
& \boldsymbol{U}_{\boldsymbol{j}=\mathbf{3}, \ldots, \mathbf{8}}=\text { ASCEasyGreen }+\alpha_{1} \text { TotalCost }+\alpha_{2} \text { Carbon }+\alpha_{3} \text { Accreditation }+\alpha_{4} \text { Contract } \\
& +\alpha_{5} \text { Location }+\alpha_{6} \text { Hydro }+\alpha_{7} \text { Solar }+\alpha_{8} \text { Wind } \\
& +\theta_{\text {Easygreen }} \mathrm{EC}_{\text {EasyGreen }}+\varepsilon_{\mathrm{j}}
\end{aligned}
$$


$\boldsymbol{U}_{\boldsymbol{j}=\mathbf{9}}=$ ASCEasyGreen + ASCMaximum $+\alpha_{1}$ TotalCost $+\alpha_{2}$ Carbon $+\alpha_{3}$ Accreditation

$+\alpha_{4}$ Contract $+\alpha_{5}$ Location $+\alpha_{6}$ Hydro $+\alpha_{7}$ Solar $+\alpha_{8}$ Wind

$+\theta_{\text {Maximum }} \mathrm{EC}_{\text {Maximum }}+\theta_{\text {EasyGreen }} \mathrm{EC}_{\text {EasyGreen }}+\varepsilon_{9}$

Natural Power

$\boldsymbol{U}_{\boldsymbol{j}=\mathbf{1 0}}=$ ASCNaturalPower + ASCMinimum $+\alpha_{1}$ TotalCost $+\alpha_{2}$ Carbon

$+\alpha_{3}$ Accreditation $+\alpha_{4}$ Contract $+\alpha_{5}$ Location $+\alpha_{6}$ Hydro $+\alpha_{7}$ Solar

$+\alpha_{8}$ Wind $+\theta_{\text {Minimum }} \mathrm{EC}_{\text {Minimum }}+\theta_{\text {NaturalPower }} \mathrm{EC}_{\text {NaturalPower }}+\varepsilon_{10}$

$\boldsymbol{U}_{\boldsymbol{j = 1 1 , 1 2}}=$ ASCNaturalPower $+\alpha_{1}$ TotalCost $+\alpha_{2}$ Carbon $+\alpha_{3}$ Accreditation

$+\alpha_{4}$ Contract $+\alpha_{5}$ Location $+\alpha_{6}$ Hydro $+\alpha_{7}$ Solar $+\alpha_{8}$ Wind

$+\theta_{\text {NaturalPower }} \mathrm{EC}_{\text {NaturalPower }}+\varepsilon_{\mathrm{j}}$

$\boldsymbol{U}_{\boldsymbol{j}=\mathbf{1 3}}=$ ASCNaturalPower + ASCMaximum $+\alpha_{1}$ TotalCost $+\alpha_{2}$ Carbon

$+\alpha_{3}$ Accreditation $+\alpha_{4}$ Contract $+\alpha_{5}$ Location $+\alpha_{6}$ Hydro $+\alpha_{7}$ Solar

$+\alpha_{8}$ Wind $+\theta_{\text {Maximum }} \mathrm{EC}_{\text {Maximum }}+\theta \mathrm{C}_{\text {NaturalPower }} \mathrm{EC}_{\text {NaturalPower }}+\varepsilon_{13}$

Earth Friendly

$\boldsymbol{U}_{\boldsymbol{j}=\mathbf{1 4}}=$ ASCEarthFriendly + ASCMinimum $+\alpha_{1}$ TotalCost $+\alpha_{2}$ Carbon

$+\alpha_{3}$ Accreditation $+\alpha_{4}$ Contract $+\alpha_{5}$ Location $+\alpha_{6}$ Hydro $+\alpha_{7}$ Solar

$+\alpha_{8}$ Wind $+\theta_{\text {Minimum }} \mathrm{EC}_{\text {Minimum }}+\theta_{\text {EarthFriendly }} \mathrm{EC}_{\text {EarthFriendly }}+\varepsilon_{14}$ 


$$
\begin{aligned}
& \boldsymbol{U}_{\boldsymbol{j}=\mathbf{1 5 , 1 6}}=\text { ASCEarthFriendly }+\alpha_{1} \text { TotalCost }+\alpha_{2} \text { Carbon }+\alpha_{3} \text { Accreditation } \\
& +\alpha_{4} \text { Contract }+\alpha_{5} \text { Location }+\alpha_{6} \text { Hydro }+\alpha_{7} \text { Solar }+\alpha_{8} \text { Wind } \\
& +\theta_{\text {EarthFriendly }} \mathrm{EC}_{\text {EarthFriendly }}+\varepsilon_{\mathrm{j}} \\
& \boldsymbol{U}_{\boldsymbol{j}=17}=\text { ASCEarthFriendly }+ \text { ASCMaximum }+\alpha_{1} \text { TotalCost }+\alpha_{2} \text { Carbon } \\
& +\alpha_{3} \text { Accreditation }+\alpha_{4} \text { Contract }+\alpha_{5} \text { Location }+\alpha_{6} \text { Hydro }+\alpha_{7} \text { Solar } \\
& +\alpha_{8} \text { Wind }+\theta_{\text {Maximum }} \mathrm{EC}_{\text {Maximum }}+\theta_{\text {EarthFriendly }} \mathrm{EC}_{\text {EarthFriendly }}+\varepsilon_{17}
\end{aligned}
$$




\section{References}

Andreoni, J. 1989. Giving with Impure Altruism: Applications to Charity and Ricardian Equivalence. Journal of Political Economy 97: 1447-1458.

Andreoni, J., 1990. Impure Altruism and Donations to Public Goods: A Theory of Warm-Glow Giving. Economic Journal 100: 464-477.

Australian National Greenhouse Accounts, 2013. National Greenhouse Accounts Factors. http://www.climatechange.gov.au/sites/climatechange/files/documents/07_2013/nationalgreenhouse-accounts-factors-july-2013.pdf

Blamey, R., J. Bennett, J.J. Louviere, M. Morrison, 2001. Green Product Choice, in: J. Bennett and R. Blamey, eds., The Choice Modelling Approach to Environmental Valuation, Edward Elgar, Cheltenham, UK.

Börsch-Supan, A. ,1990. On the compatibility of nested logit models with utility maximization. Journal of Econometrics 43: 373-388.

Collins, A., J.M. Rose, S. Hess, 2012. Interactive stated choice surveys: a study of air travel behavior. Transportation 39(1): 55-79.

Conte, M.N, G.D. Jacobsen, 2014. When Do Voluntary Environmental Programs Succeed? Evidence from Green Electricity and All U.S. Utilities. Working Paper.

Diaz-Rainey, I., D. Tzavara, 2012. Financing the Decarbonized Energy System Through Green Electricity Tariffs: A Diffusion Model of an Induced Consumer Environmental Market. Technological Forecasting and Social Change 79(9): 1693-1704.

$\begin{array}{llll}\text { Department } & \text { of } & \text { Energy, } & \end{array}$ http://apps3.eere.energy.gov/greenpower/markets/pricing.shtml?page $=0$, last accessed on October $9^{\text {th }}, 2015$.

Ek, K., P. Söderholm, 2008. Norms and economic motivation in the Swedish green electricity market. Ecological Economics 68: 169-182.

Farhar, B., 1999. Willingness to Pay for Electricity from Renewable Resources: A Review of Utility Market Research. NREL/TP.550.26148. Golden, CO: National Renewable Energy Laboratory.

Farhar, B.C., A. H. Houston, 1996. Willingness to Pay for Electricity from Renewable Energy. 
NERL Report No. TP-460-21216, National Renewable Energy Laboratory, Golden, Colorado, USA.

Goett, A.A., K. Hudson, K.E. Train, 2000. Customers Choice among Retail Energy Suppliers: The Green Power (2013). National GreenPower Accreditation Program Status Report Quarter 2. http://www.greenpower.gov.au/ /media/Business\%20Centre/Quarterly\%20Reports/2013Q2R eport.pdf.

GreenPower, 2015. Quarterly Audit Report, available at: http://www.greenpower.gov.au/News/Q1-2015-Quaterly-Report-has-been-

published/ /media/9C7FB6E1CBA54122A0A6DCAC3E7FFCE8.pdf, last accessed on October $9^{\text {th }}, 2015$.

Harbaugh, W. T., 1998. What do donations buy? a model of philanthropy based on prestige and warm glow. Journal of Public Economics 67(2): 269-284.

Harding, M., Rapson, D., 2013. Does Absolution Promote Sin? The Conservationist's Dilemma. University of California at Davis, Working Paper.

Hensher, D.A, J.M Rose, W.H. Greene, 2005. Applied Choice Analysis A Primer. Cambridge University Press.

Hess, S., D.A. Hensher, 2013. Making Use of Respondent Reported Processing Information to Understand Attribute Importance: A Latent Variable Scaling Approach. Transportation 40: 397412.

Ivanova, G., 2012. Are Consumers Willing to Pay Extra for the Electricity from Renewable Energy Sources? An example of Queensland, Australia. International Journal of Renewable Energy Research 2 (4): 758-766.

Jacobsen, G.D., M.J. Kotchen, M.P. Vandenbergh, 2012. The behavioral response to voluntary provision of an environmental public good: Evidence from residential electricity demand. European Economic Review 56: 946-960.

Kahneman, D., J. L. Knetsch, 1992. Valuing Public Goods: The Purchase of Moral Satisfaction. Journal of Environmental Economics and Management 22: 57-70.

Kotchen, M.J., M.R. Moore, 2007. Private provision of environmental public goods: Household participation in green-electricity programs. Journal of Environmental and Economics and Management 53: 1-16. 
Kotchen, M. J., M. R. Moore. 2008. Conservation: From voluntary restraint to a voluntary price premium. Environmental and Resource Economics 40:195-215.

Landor Associates, 2011. Green Brands Survey 2011. http://www.psbresearch.in/pdf/greenbrands-survey-2011-global.pdf

Louviere, J.J., D.A. Hensher, J. Swait, 2000. Stated Choice Methods: Analysis and Applications in Marketing. Cambridge: Cambridge University Press.

Menges, R., C. Schroeder, S. Traub, 2005. Altruism, Warm Glow and the Williness-to-Donate for Green Electricity: An Artefactual Field Experiment. Environmental and Resource Economics 31: 431 458.

Mewton, R.T, O.J. Cacho, 2011. Green Power voluntary purchases: Price elasticity and policy analysis. Energy Policy 39: 377-385.

Navrud, S., K.G. Bråten, 2007. Consumers' Preferences for Green and Brown Electricity: a Choice Modelling Approach. Revue d'économie politique 5 (117): 795-811.

Nomura, N., M. Akai, 2004. Willingness to pay for green electricity in Japan as estimated through contingent valuation method. Applied Energy 78: 453-463.

Nunes,A.L.D., E. Schokkaert, 2003. Identifying the warm glow effect in contingent valuation. Journal of Environmental Economics and Management 45: 231-245

Oberholzer-Gee, Felix, 2001. Your Contribution Counts! An Empirical Analysis of the Decision to Support Solar Energy, in Environmental Voluntary Contracts: Comparative Approaches to Regulation Innovation in the United States and Europe, Eric W. Orts and Kurt Deketelaere (Eds.), London: Kluwer Law International, pp. 425-34.

Perino, G., 2015. Climate Campaigns, Cap and Trade, and Carbon Leakage: Why Trying to Reduce Your Carbon Footprint Can Harm the Climate. Journal of the Association of Environmental and Resource Economists 2(3): 469-495.

Rose, J., M. Bliemer. Ngene. Available from: http://www.choice-metrics.com/download.html Rowlands, I., D. Scott, P. Parker, 2003. Consumers and green electricity: Profiling potential purchasers. Business and Strategy and the Environment 12: 36-48.

Rose-Ackerman, S. 1982. Charitable giving and "excessive" fundraising. Quarterly Journal of Economics, 97:193-212.

Salmela, S., V. Varho, 2006. Consumers in the green electricity market in Finland. Energy Policy 34: 
3669-3683.

Scarpa, R., J. Rose, 2008. Design efficiency for non-market valuation with choice modelling: how to measure it, what to report and why. Australian Journal of Agricultural and Resource Economics 52: 253-282

Scarpa, R., K. Willis, 2010. Willingness-to-pay for renewable energy: Primary and discretionary choice of British households' for micro-generation technologies. Energy Economics 32: 129-136.

Synergy, 2013. Electricity Retail Indicators 2012-2013 Year in Review. http://www.synergy.net.au/docs/Electricity_Retail_Indicators_2012_13_Year_in_review.pdf.

Train, K., 2009. Discrete Choice Models with Simulation, $2^{\text {nd }}$ Edition, Cambridge University Press, Cambridge

von Haefen, R.H., D.M. Massey, W.L. Adamowicz, 2005. Serial Nonparticipation in Repeated Discrete Choice Models. American Journal of Agricultural Economics 87(4): 1061-1076.

Walker, J.L., M. Ben-Akiva, D. Bolduc, 2007. Identification of Parameters in Normal Error Component Logit-Mixture (NECLM) Models. Journal of Applied Econometrics 22 (6): 1095-1125.

Wiser, R.H., 2007. Using contingent valuation to explore willingness to pay for renewable energy: A comparison of collective and voluntary payment vehicles. Ecological Economics 62: 419-432. 


\section{Supplementary Material}

In the main text, we have reported results from models in which self-reported attitudinal variables (ClimateNo, ClimateUnsure, GreenParty, TrustUt and TrustGov) are excluded due to endogeneity concerns (Hess and Hensher, 2013). However, it is still quite common for empirical choice modelling research to include such variables. We thus re-estimate the models with these variables included in the utility function for the conventional power and report the results in Table 10. Table 11 reports results from models using the full sample that include respondents having repeat preferences. Although not reported here, we also simulate all marginal effects that are equivalent to those reported in Table $\mathbf{6 , 7 , 8}$ and $\mathbf{9}$. These results are available from the authors upon request. Conte and Jacobsen (2014) find that the education of the consumer base is one of the key determinants the participation rate in green electricity programs. However, educational variables are found to be statistically insignificant in the ECM using the sub-sample excluding respondents having "repeat conventional" preferences. We re-estimate the models using the full sample and present the results in Table 12. Here we find that educational levels are negatively associated the choice of conventional power which is consistent with Conte and Jacobsen (2014). The difference between Table 5 in the text and Table 12 here also suggests that education plays a significant role in converting consumers with repeat preference for conventional power to possible participants of green electricity programs but appears insignificant in the choice among products once they become "possible" participants. Table 13 includes age and income variables (but no attitudinal) variables using the income-restricted sample. As not all respondents disclose income information, the income-restricted sample is significantly smaller than the one reported in Table 5. It appears that participation in green 
electricity programs is positively associated with income levels. Our general conclusions do not change with these alternatively specified models.

Table 10: Results from ECM with Attitudinal Variables

\begin{tabular}{lrrrrr}
\hline \multicolumn{1}{c}{ Attributes } & & Coefficienttt & Z-stat. & Lower 95\% & Upper 95\% \\
\hline Common to all alternatives & & & & & \\
Specific to conventional & TotalCost & $-0.081^{* *}$ & -19.46 & -0.090 & -0.073 \\
& & & & & \\
& Female & $-0.698^{*}$ & -2.21 & -1.318 & -0.079 \\
Age & -0.006 & -0.58 & -0.027 & 0.015 \\
HighSchool & -2.795 & -1.34 & -6.881 & 1.290 \\
TertiaryUnder & --3.534 & -1.7 & -7.602 & 0.535 \\
TertiaryPost & -2.694 & -1.29 & -6.788 & 1.401 \\
TradeTAFE & -2.906 & -1.39 & -6.993 & 1.182 \\
ClimateNo & $1.212^{*}$ & 2.01 & 0.033 & 2.392 \\
ClimateUnsure & $1.542^{* *}$ & 3.51 & 0.682 & 2.403 \\
GreenParty & $-2.388^{* *}$ & -4.56 & -3.413 & -1.362 \\
TrustUt & $-0.604^{* *}$ & -3.46 & -0.947 & -0.262 \\
TrustGov & -0.145 & -0.83 & -0.488 & 0.198
\end{tabular}

Specific to green products

\begin{tabular}{rrrrr} 
Carbon & $0.041^{* *}$ & 4.32 & 0.022 & 0.060 \\
Accreditation & $0.221^{* *}$ & 8.53 & 0.170 & 0.271 \\
Contract & $-0.198^{* *}$ & -7.21 & -0.252 & -0.144 \\
Location & $0.257^{* *}$ & 9.51 & 0.204 & 0.310 \\
Hydro & 0.033 & 0.73 & -0.056 & 0.122 \\
Solar & $0.131^{* *}$ & 2.89 & 0.042 & 0.219 \\
Wind & 0.028 & 0.63 & -0.058 & 0.113 \\
ASCEasyGreen & $-7.376^{* *}$ & -3.35 & -11.693 & -3.059 \\
ASCNaturalPower & $-7.045^{* *}$ & -3.20 & -11.361 & -2.730 \\
ASCEarthFriendly & $-7.545^{* *}$ & -3.43 & -11.858 & -3.232 \\
ASCMinimum & $1.530^{* *}$ & 11.33 & 1.266 & 1.795 \\
ASCMaximum & $-1.053^{* *}$ & -3.49 & -1.644 & -0.461 \\
\hline & & & & \\
ECConventional & $3.129^{* *}$ & 16.74 & 2.763 & 3.496 \\
ECEasyGreen & $1.675^{* *}$ & 14.46 & 1.448 & 1.901
\end{tabular}




\begin{tabular}{rrrrr} 
ECNaturalPower & -0.359 & -1.83 & -0.743 & 0.026 \\
ECEartbFriendly & $-1.236^{* *}$ & -11.33 & -1.450 & -1.022 \\
ECMinimum & $2.723^{* *}$ & 18.34 & 2.432 & 3.014 \\
ECMaximum & $-3.014^{* *}$ & -11.36 & -3.534 & -2.494 \\
\hline
\end{tabular}

Maximized log likelihood (LL) ttt -6815.790 .

Wald chi squared $1350.76^{* *}$

Number of obs. $72726+t$

†** and $*$ denotes significance level at $1 \%$ and 5 ; tt Respondents with "repeat conventional" preferences are removed from the sample; tttLL values for alternative specifications comparable to those presented in Table 5 are available upon request. 
Table 11: Results from ECM with Full Sample and Attitudinal Variables

\begin{tabular}{|c|c|c|c|c|}
\hline Attributes & Coefficient ${ }^{\dagger}$ & Z-stat. & Lower $95 \%$ & Upper $95 \%$ \\
\hline \multicolumn{5}{|l|}{ Common to all alternatives } \\
\hline TotalCost & $-0.082^{* *}$ & -19.34 & -0.090 & -0.074 \\
\hline \multicolumn{5}{|l|}{ Specific to conventional } \\
\hline Female & $-1.077 * *$ & -3.16 & -1.744 & -0.410 \\
\hline Age & 0.004 & 0.34 & -0.019 & 0.028 \\
\hline HighSchool & $-4.524^{*}$ & -2.41 & -8.206 & -0.843 \\
\hline TertiaryUnder & $-5.818^{* *}$ & -3.11 & -9.487 & -2.150 \\
\hline TertiaryPost & $-5.290 * *$ & -2.80 & -8.988 & -1.592 \\
\hline Trade'TAFE & $-4.885^{* *}$ & -2.61 & -8.554 & -1.215 \\
\hline ClimateNo & $2.136 * *$ & 3.59 & 0.968 & 3.303 \\
\hline ClimateUnsure & $1.830^{* *}$ & 4.05 & 0.945 & 2.715 \\
\hline GreenParty & $-2.781 * *$ & -4.80 & -3.917 & -1.646 \\
\hline TrustUt & $-0.451 *$ & -2.28 & -0.838 & -0.064 \\
\hline TrustGov & $-0.488^{*}$ & -2.39 & -0.889 & -0.087 \\
\hline \multicolumn{5}{|l|}{ Specific to green products } \\
\hline Carbon & $0.042 * *$ & 4.40 & 0.023 & 0.061 \\
\hline Accreditation & $0.220^{* *}$ & 8.51 & 0.169 & 0.271 \\
\hline Contract & $-0.197 * *$ & -7.15 & -0.251 & -0.143 \\
\hline Location & $0.255^{* *}$ & 9.45 & 0.202 & 0.308 \\
\hline Hydro & 0.032 & 0.70 & -0.057 & 0.120 \\
\hline Solar & $0.128^{* *}$ & 2.84 & 0.040 & 0.217 \\
\hline Wind & 0.025 & 0.58 & -0.060 & 0.111 \\
\hline ASCEasyGreen & $-10.378^{* *}$ & -5.20 & -14.292 & -6.463 \\
\hline ASCNaturalPower & $-10.053^{* *}$ & -5.04 & -13.962 & -6.145 \\
\hline ASCEarthFriendly & $-10.582^{* *}$ & -5.31 & -14.491 & -6.673 \\
\hline ASCMinimum & $1.495^{* *}$ & 10.54 & 1.217 & 1.773 \\
\hline ASCMaximum & $-1.248^{* *}$ & -3.90 & -1.875 & -0.620 \\
\hline \multicolumn{5}{|l|}{ Error Components } \\
\hline ECConventional & $3.789 * *$ & 17.96 & 3.375 & 4.203 \\
\hline ECEasyGreen & $1.672^{* *}$ & 14.53 & 1.447 & 1.898 \\
\hline ECNaturalPower & -0.222 & -0.95 & -0.679 & 0.235 \\
\hline ECEarthFriendly & $-1.298^{* *}$ & -12.63 & -1.499 & -1.097 \\
\hline ECMinimum & $-2.913^{* *}$ & -17.58 & -3.238 & -2.589 \\
\hline ECMaximum & $-3.042 * *$ & -11.78 & -3.548 & -2.536 \\
\hline Maximized log likelihood (LL) †† & \multicolumn{4}{|c|}{-6970.932} \\
\hline Wald chi squared & \multicolumn{4}{|c|}{$1444.25^{* *}$} \\
\hline Number of obs. & \multicolumn{4}{|c|}{84762} \\
\hline
\end{tabular}


†** and $*$ denotes significance level at $1 \%$ and $5 \%$; + LL values for alternative specifications comparable to those presented in Table 5 are available upon request. 
Table 12: Results from ECM with Full Sample and No Attitudinal Variables

\begin{tabular}{|c|c|c|c|c|}
\hline Attributes & Coefficient $^{\dagger}$ & Z-stat. & Lower $95 \%$ & Upper $95 \%$ \\
\hline \multicolumn{5}{|l|}{ Common to all alternatives } \\
\hline TotalCost & $-0.081 * *$ & -19.33 & -0.089 & -0.073 \\
\hline \multicolumn{5}{|l|}{ Specific to conventional } \\
\hline Female & $-1.288 * *$ & -3.74 & -1.963 & -0.612 \\
\hline Age & 0.014 & 1,20 & -0.009 & 0.038 \\
\hline HighSchool & -4.095 & -1.92 & -8.275 & 0.084 \\
\hline TertiaryUnder & $-5.567 * *$ & -2.62 & -9.732 & -1.402 \\
\hline TertiaryPost & $-5.373 *$ & -2.51 & -9.576 & -1.169 \\
\hline Trade'TAFE & $-4.324 *$ & -2.03 & -8.505 & -0.144 \\
\hline \multicolumn{5}{|l|}{ Specific to green products } \\
\hline Carbon & $0.041 * *$ & 4.31 & 0.022 & 0.060 \\
\hline Accreditation & $0.220^{* *}$ & 8.54 & 0.170 & 0.271 \\
\hline Contract & $-0.195^{* *}$ & -7.10 & -0.249 & -0.141 \\
\hline Location & $0.255^{* *}$ & 9.45 & 0.202 & 0.307 \\
\hline Hydro & 0.028 & 0.61 & -0.061 & 0.116 \\
\hline Solar & $0.127 * *$ & 2.81 & 0.038 & 0.215 \\
\hline Wind & 0.027 & 0.61 & -0.059 & 0.112 \\
\hline ASCEasyGreen & $-7.564 * *$ & -3.59 & -11.694 & -3.434 \\
\hline ASCNaturalPower & $-7.231 * *$ & -3.44 & -11.357 & -3.106 \\
\hline ASCEartbFriendly & $-7.769 * *$ & -3.69 & -11.893 & -3.645 \\
\hline ASCMinimum & $1.439 * *$ & 10.20 & 1.162 & 1.715 \\
\hline ASCMaximum & $-1.146^{* *}$ & -3.52 & -1.783 & -0.509 \\
\hline \multicolumn{5}{|l|}{ Error Components } \\
\hline ECConventional & $4.076^{* *}$ & 17.55 & 3.621 & 4.532 \\
\hline ECEasyGreen & $1.703^{* *}$ & 14.69 & 1.476 & 1.931 \\
\hline ECNaturalPower & -0.039 & -0.18 & -0.466 & 0.387 \\
\hline ECEarthFriendly & $-1.264 * *$ & -13.08 & -1.454 & -1.075 \\
\hline ECMinimum & $-2.990 * *$ & -17.49 & -3.325 & -2.655 \\
\hline ECMaximum & $2.978^{* *}$ & 11.68 & 2.478 & 3.478 \\
\hline Maximized log likelihood (LL) ${ }^{\text {tt }}$ & \multicolumn{4}{|c|}{-7016.09} \\
\hline Wald chi squared & \multicolumn{4}{|c|}{$1398.37 * *$} \\
\hline Number of obs. & \multicolumn{4}{|c|}{84762} \\
\hline
\end{tabular}

$\dagger_{* *}$ and $*$ denotes significance level at $1 \%$ and $5 \%$; ${ }^{\dagger+}$ LL values for alternative specifications comparable to those presented in Table $\mathbf{5}$ are available upon request. 
Table 13: Results from ECM with Additional Income Variables and No Attitudinal Variables

\begin{tabular}{|c|c|c|c|c|}
\hline Attributes & Coefficient ${ }^{\dagger}$ & Z-stat. & Lower $95 \%$ & Upper $95 \%$ \\
\hline \multicolumn{5}{|l|}{ Common to all alternatives } \\
\hline TotalCost & $-0.078 * *$ & -18.33 & -0.086 & -0.070 \\
\hline \multicolumn{5}{|l|}{ Specific to conventional } \\
\hline Female & $-1.113^{* *}$ & -3.90 & -1.672 & -0.554 \\
\hline Age & -0.016 & -1.49 & -0.037 & 0.005 \\
\hline HighSchool & -0.588 & -0.55 & -2.664 & 1.488 \\
\hline TertiaryUnder & -1.464 & -1.39 & -3.535 & 0.606 \\
\hline TertiaryPost & -0.981 & -0.89 & -3.140 & -1.178 \\
\hline TradeTAFE & -0.617 & -0.58 & -2.710 & 1.476 \\
\hline$\$ 40,000<$ Income $^{\text {tt }}<\$ 70,000$ & 0.154 & 0.36 & -0.673 & 0.981 \\
\hline$\$ 70,000<$ Income $^{\text {tt }}<\$ 100,000$ & $-1.193 * *$ & -2.62 & -2.085 & -0.301 \\
\hline$\$ 100,000<$ Income $^{\mathrm{tt}}<\$ 130,000$ & -0.462 & -0.99 & -1.379 & 0.455 \\
\hline Income $^{\mathrm{tt}}>\$ 130,000$ & $-0.955^{*}$ & -2.08 & -1.854 & -0.057 \\
\hline
\end{tabular}

Specific to green products

\begin{tabular}{rrrrr} 
Carbon & $0.039 * *$ & 3.97 & 0.020 & 0.058 \\
Accreditation & $0.223^{* *}$ & 8.24 & 0.170 & 0.276 \\
Contract & $-0.206^{* *}$ & -7.13 & -0.262 & -0.149 \\
Location & $0.255^{* *}$ & 9.03 & 0.200 & 0.311 \\
Hydro & 0.031 & 0.65 & -0.062 & 0.123 \\
Solar & $0.120^{*}$ & 2.53 & 0.027 & 0.213 \\
Wind & 0.031 & 0.67 & -0.059 & 0.120 \\
ASCEasyGreen & $-4.409^{* *}$ & -4.03 & -6.552 & -2.267 \\
ASCNaturalPower & $-4.097^{* *}$ & -3.77 & -6.228 & -1.965 \\
ASCEarthFriendly & $-4.562^{* *}$ & -4.20 & -6.692 & -2.431 \\
ASCMinimum & $1.287^{* *}$ & 10.69 & 1.051 & 1.523 \\
ASCMaximum & $-1.221^{* *}$ & -4.20 & -1.791 & -0.651 \\
\hline ECConventional & $3.015^{* *}$ & 17.79 & 2.683 & 3.347 \\
ECEasyGreen & $1.714^{* *}$ & 13.42 & 1.464 & 1.965 \\
ECNaturalPower & $-0.360^{*}$ & -2.55 & -0.637 & -0.083 \\
ECEarthFriendly & $1.217 * *$ & 11.62 & 1.012 & 1.422 \\
ECMinimum & $2.477^{* *}$ & 18.46 & 2.214 & 2.740 \\
ECMaximum & $3.264^{* *}$ & 13.75 & 2.799 & 3.729 \\
\hline
\end{tabular}

Maximized log likelihood (LL) ${ }^{\text {t+ }}$

$-6231.41$

Wald chi squared

$1330.04 * *$

Number of obs.

65586

$\overline{\dagger * *}$ and $*$ denotes significance level at $1 \%$ and $5 \%$; ${ }^{\text {t十 }} \mathrm{LL}$ values for alternative specifications 
comparable to those presented in Table $\mathbf{5}$ are available upon request. 